The University of Maine

DigitalCommons@UMaine

Marine Sciences Faculty Scholarship

School of Marine Sciences

$1-1-2019$

\title{
The plankton, aerosol, cloud, ocean ecosystem mission status, science, advances
}

\author{
P. Jeremy Werdell \\ NASA Goddard Space Flight Center \\ Michael J. Behrenfeld \\ Oregon State University \\ Paula S. Bontempi \\ National Aeronautics and Space Administration \\ Emmanuel Boss \\ University of Maine, emmanuel.boss@maine.edu \\ Brian Cairns \\ NASA Goddard Space Flight Center
}

See next page for additional authors

Follow this and additional works at: https://digitalcommons.library.umaine.edu/sms_facpub

Part of the Oceanography and Atmospheric Sciences and Meteorology Commons

\section{Repository Citation}

Werdell, P. Jeremy; Behrenfeld, Michael J.; Bontempi, Paula S.; Boss, Emmanuel; Cairns, Brian; Davis, Gary T.; Franz, Bryan A.; Gliese, Ulrik B.; Gorman, Eric T.; Hasekamp, Otto; Knobelspiesse, Kirk D.; Mannino, Antonio; Martins, J. Vanderlei; McClain, Charlesr; Meister, Gerhard; and Remer, Lorraine A., "The plankton, aerosol, cloud, ocean ecosystem mission status, science, advances" (2019). Marine Sciences Faculty Scholarship. 174.

https://digitalcommons.library.umaine.edu/sms_facpub/174

This Article is brought to you for free and open access by DigitalCommons@UMaine. It has been accepted for inclusion in Marine Sciences Faculty Scholarship by an authorized administrator of DigitalCommons@UMaine. For more information, please contact um.library.technical.services@maine.edu. 


\section{Authors}

P. Jeremy Werdell, Michael J. Behrenfeld, Paula S. Bontempi, Emmanuel Boss, Brian Cairns, Gary T. Davis, Bryan A. Franz, Ulrik B. Gliese, Eric T. Gorman, Otto Hasekamp, Kirk D. Knobelspiesse, Antonio Mannino, J. Vanderlei Martins, Charlesr McClain, Gerhard Meister, and Lorraine A. Remer 


\title{
THE PLANKTON, AEROSOL, CLOUD, OCEAN ECOSYSTEM MISSION Status, Science, Advances
}

\author{
P. Jeremy Werdell, Michael J. Behrenfeld, Paula S. Bontempi, Emmanuel Boss, Brian Cairns, Gary T. Davis, \\ Bryan A. Franz, Ulrik B. Gliese, Eric T. Gorman, Otto Hasekamp, Kirk D. Knobelspiesse, Antonio Mannino, \\ J. Vanderlei Martins, Charles R. McClain, Gerhard Meister, and Lorraine A. Remer
}

The PACE mission represents NASA's next investment in ocean color, cloud, and aerosol data records to enable continued and advanced insight into oceanographic and atmospheric responses to Earth's changing climate.

T he Plankton, Aerosol, Cloud, ocean Ecosystem (PACE; https://pace.gsfc.nasa.gov) mission represents the National Aeronautics and Space Administration's (NASA) next advance in satellite ocean color and polarimetry for the combined study of Earth's ocean-atmosphere-land system. Its multidisciplinary observations will serve the oceanographic, atmospheric, and terrestrial science communities, building upon a recognition that significant synergies exist between measurement requirements for atmospheric and aquatic ecosystem remote sensing retrievals of geophysical properties. PACE observations will enable continuation of climate research-quality long-term data records established by a diversity of heritage U.S. and international Earth-observing satellite missions. The underlying motivation for the mission, however, has long been to provide advanced observational capabilities enabling a leap forward in
Affiliations: Werdell, Franz, Knobelspiesse, Mannino, Meister, AND MCCLAIN*_Ocean Ecology Laboratory, NASA Goddard Space Flight Center, Greenbelt, Maryland; BeHrenfelD-Department of Botany and Plant Pathology, Oregon State University, Corvallis, Oregon; BONTEMPI-Earth Sciences Division, NASA Headquarters, Washington, D.C.; Boss-School of Marine Sciences, University of Maine, Orono, Maine; CAIRNs-Goddard Institute of Space Sciences, NASA Goddard Space Flight Center, New York, New York; DAvIs-Mission Systems Engineering Branch, NASA Goddard Space Flight Center, Greenbelt, Maryland; GLIESE-Instrument Projects Division, NASA Goddard Space Flight Center, Greenbelt, Maryland; GoRMAN-Systems Engineering Services and Advanced Concepts Branch, NASA Goddard Space Flight Center, Greenbelt, Maryland; HASEKAMP-SRON, Netherlands Institute of Space Research, Utrecht, Netherlands; MARTINS AND Remer-Joint Center for Earth
Systems Technology, University of Maryland, Baltimore County, Baltimore, Maryland

* Retired CORRESPONDING AUTHOR: P. Jeremy Werdell, jeremy.werdell@nasa.gov

The abstract for this article can be found in this issue, following the table of contents. DOI:10.II75/BAMS-D-I8-0056.I

In final form 18 April 2019

(C)2019 American Meteorological Society

For information regarding reuse of this content and general copyright information, consult the AMS Copyright Policy. 
Earth system understanding ("Core science objectives, questions, and applications" sidebar).

One central objective of the PACE mission is to gain new insights on aquatic ecology and biogeochemistry and their sensitivity to environmental change. Global satellite measurements of passive water-leaving reflectances (i.e., "ocean color") began with the Coastal Zone Color Scanner (CZCS; 197886) and have been continued by the Sea-Viewing Wide Field-of-View Sensor (SeaWiFS; 1997-2010), the Moderate Resolution Imaging Spectroradiometers (MODIS) on board Terra (1999-present) and Aqua (2002-present), Medium Resolution Imaging Spectrometer (MERIS; 2002-12), the Visible Infrared Imaging Radiometer Suite (VIIRS) on board Suomi National Polar-Orbiting Partnership (Suomi NPP; 2012-present) and National Oceanic and Atmospheric Administration (NOAA)-20 (2017-present), the Ocean and Land Colour Instrument (OLCI) on board Sentinel-3A (2016-present) and Sentinel3B (2018-present), and the Second-Generation Global Imager (SGLI; 2017-present). These missions provided a desperately needed wide-angle lens for observing what had previously been the grossly undersampled ocean ecosystems of Earth (Fig. 1). The resultant satellite era in oceanography revolutionized our understanding of aquatic systems, their crucial role to this living planet, and their sensitivity to climate variability (McClain 2009; National Research Council 2011; Siegel et al. 2004a,b; Zibordi et al. 2014). Even with these major achievements (and also because of them), however, the oceanographic community recognized the need for enhanced measurement capabilities to address issues of global phytoplankton physiology, ecosystem and habitat health, and carbon fluxes (ACE Ocean Working Group 2018).

Another driving objective of the PACE mission is the retrieval of heritage and advanced atmospheric

\section{CORE SCIENCE OBIECTIVES, OUESTIONS, AND APPLICATIONS}

DACE's core objectives, questions, and applications dictated mission requirements that shaped the Ocean Color Instrument design and resulted in the inclusion of multiangle polarimetry on the observatory. Mission science objectives evolved from the ACE experience through the Science Definition Team (SDT):

I) extend key systematic ocean biological, ecological, and biogeochemical climate data records and cloud and aerosol climate data records;

2) make new global measurements of ocean color to improve our understanding of the carbon cycle and ocean ecosystem responses to a changing climate;

3) collect global observations of aerosol and cloud properties, focusing on reducing the largest uncertainties in climate and radiative forcing models of the Earth system; and

4) improve our understanding of how aerosols influence ocean biogeochemical cycles and ecosystems and how ocean biological and photochemical processes affect the atmosphere.

The SDT translated these objectives into questions to be addressed, which we paraphrase as follows:
I) How is Earth changing and what are the consequences for our living resources and food webs, such as phytoplankton? What is the concentration and composition of phytoplankton in the ocean and how productive are oceanic ecosystems? How are biological, geological, and chemical components of our ocean changing and why? What are the distributions of harmful and beneficial algal blooms and how are they related to environmental forces?

2) What are the long-term changes in aerosol and cloud properties that PACE can continue to reveal? How do clouds affect aerosol properties in regions near cloud boundaries? What are the magnitudes and trends of direct aerosol radiative forcing, including its anthropogenic component? How are these properties correlated with variations in interannual climate oscillations?

3) How do atmospheric aerosols influence ocean ecosystems and cycling of matter in our ocean? How do ocean processes affect our atmosphere? How do such changes influence the Earth system?

4) What materials are exchanged between the land and ocean? How do these exchanges affect life on our coasts? How do human activities affect ocean ecosystems and services and how do changes in these affect people's health and welfare?

Simultaneously, key applications and societal benefits to be realized by PACE emerged. Its aerosol products will support air quality forecasts to aid in issuing human health advisories. Expanding our understanding of radiative forcing effects of clouds and aerosols will improve parameterization of climate models to aid policymakers with decisions related to climate change issues. PACE ocean products will provide insight into aquatic ecosystem health, water quality and related human health issues, and ecological forecasting of marine resources including fisheries. Measurements of phytoplankton biomass, composition, and production will benefit ecosystem-based models, which aid in managing fisheries. Coastal resource managers and policymakers will gain access to data products that inform on water clarity, nutrient loading, and detection and identification of harmful algal blooms (HABs) that can harm humans through the consumption of contaminated seafood and inhalation of toxins. Knowledge of the presence of HABs allow local, state, and federal officials to close fishing grounds and beaches to mitigate harm to humans. 
data products, with an eye on reducing uncertainties in global climate models and improving our interdisciplinary understanding of the ocean-atmosphere system. As with ocean satellite remote sensing, heritage satellite radiometers [those listed above, as well as the Multiangle Imaging SpectroRadiometer (MISR; 1999-present), the Polarization and Directionality of the Earth's Reflectances (POLDER) instrument on board Polarization and Anisotropy of Reflectances for Atmospheric Sciences Coupled with Observations from a Lidar (PARASOL; 2004-13), and others] revolutionized our understanding of the atmosphere (Fig. 1). For example, the characterization of atmospheric aerosols on global scales enabled visualization of Earth's aerosol system and estimation of climatescale aerosol radiative effects (e.g., Kaufman et al. 2002; Yu et al. 2006), while also providing critical data for air quality monitoring (Al-Saadi et al. 2005; Hoff and Christopher 2009). Characterization of cloud properties enabled generation of global-scale cloud parameter statistics and insights into climate-relevant cloud processes from aerosol-cloud interactions (Costantino and Breon 2010; Kaufman et al. 2005; Yuan et al. 2016). Despite these substantial achievements, significant advances in measurement capabilities are needed to better constrain aerosol and cloud properties and improve our understanding of effective radiative forcing (National Research Council 2007).
The PACE observatory includes three science instruments, the combination of which advances far beyond the heritage measurement capabilities previously described. The primary Ocean Color Instrument (OCI) consists of two spectrometers that continuously span the ultraviolet to orange and orange to near-infrared spectral regions. Additional detectors will collect measurements at seven discrete shortwave-infrared (SWIR) bands, six of which are at similar wavelengths to those on heritage missions to support both atmospheric and ocean color applications. Importantly, the two longest bands $(2,130 \mathrm{~nm}$ as on MODIS and 2,260 $\mathrm{nm}$ as on VIIRS) will facilitate new observations of cloud properties (Coddington et al. 2017). The PACE observatory also includes two small multiangle polarimeters with spectral ranges that span the visible to near-infrared (NIR) region. Scheduled for launch in late 2022 to early 2023, this advanced suite of instruments will enable new insights into oceanographic and atmospheric responses to Earth's changing climate. The PACE mission will provide previously unavailable information for the management of fisheries, large freshwater bodies, and water and air quality. PACE's hyperspectral observations will also provide valuable information on the radiative properties of land surfaces and on characterization of vegetation and soils that complement Landsat's narrow-swath

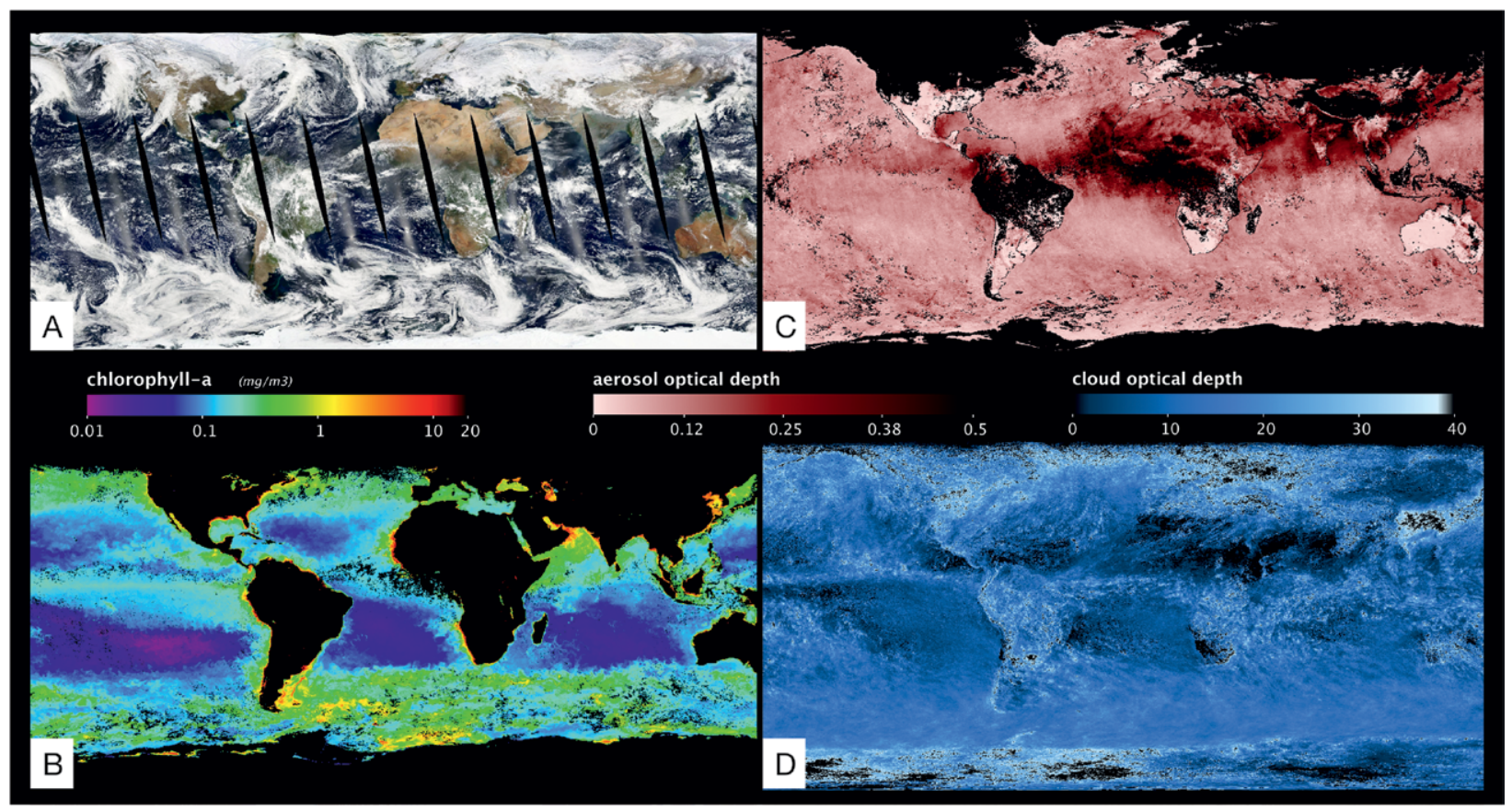

FIG. I. Example global imagery from MODIS Aqua, representing several data products to be produced by PACE's ocean color instrument: (a) true color from 10 Jan 2019, (b) average concentrations of chlorophyll a for Jan 2019 , (c) average aerosol optical depth for Jan 2019, and (d) average cloud optical depth for Jan 2019. Data acquired from NASA Earth Observations (https://neo.sci.gsfc.nasa.gov). 
and high-spatial-resolution data. Here, we provide a brief history of the science communities' efforts leading to the PACE mission, an overview of the science objectives that defined mission observational requirements, a description of the PACE observatory and postlaunch data processing strategy, and a brief overview of programmatic aspects of the mission.

\section{REALIZING PACE: A BRIEF HISTORY.} Heritage satellite ocean color sensors typically collect(ed) measurements over a limited set of broad visible (e.g., 10-20 nm) and NIR (e.g., 20-40 nm) bands, where the visible bands provide information on ocean properties and the NIR bands enable atmospheric correction (Mobley et al. 2016). For the U.S. ocean color sensors, the number of visible bands increased from CZCS to SeaWiFS to MODIS, then decreased with VIIRS, most notably in the spectral range required to detect chlorophyll fluorescence (Fig. 2). Over the same time period, scientific applications and approaches for extracting important information from ocean color data increased exponentially. The community began recognizing the growing contrast between science and measurement capabilities following the launch of SeaWiFS. Accordingly, NASA and members of the remote sensing oceanographic community began a discussion in 2000 to define observational capabilities for a future satellite mission that would meet growing

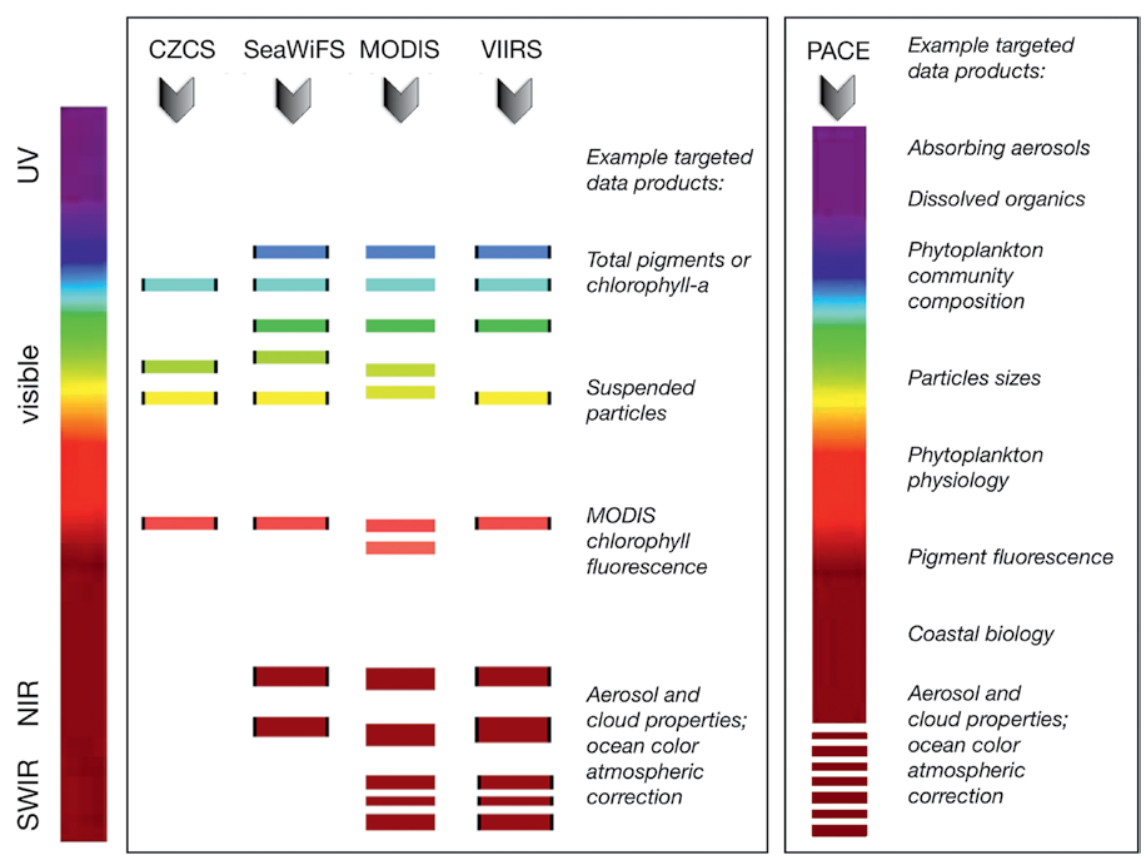

FIG. 2. Spectral capabilities of several heritage satellite radiometers in comparison with PACE, highlighting examples of associated data products that can be retrieved with such capabilities. needs for scientific discovery (McClain et al. 2002). These desired capabilities increased over time to eventually become what is now the PACE mission.

The first iteration of an advanced mission concept envisioned a single ocean color radiometer, most easily described as an enhanced SeaWiFS with additional wavelengths. This evolved into a second mission concept that paired the improved ocean color radiometer with atmosphere and ocean measurements from a satellite lidar. This subsequent concept, the Physiology and Lidar Mission (PhyLM), included multiple instrument and mission design studies conducted at the NASA Goddard Space Flight Center (GSFC). The addition of a lidar created a mission that benefitted both atmospheric and ocean sciences, including, for the latter community, improved skill in atmospheric correction and new information on subsurface vertical structure in plankton properties. Lidar measurements, however, do not provide spatial coverage comparable to a wide-swath ocean color sensor. To address this, the PhyLM concept expanded to include atmospheric (and some aquatic) retrievals from a polarimeter, resulting in the three-instrument Ocean Carbon, Ecosystem, and Nearshore (OCEaNS) mission concept. As this concept evolved, the number of desired wavelengths increased to facilitate emerging methods for determining ocean ecosystem community composition, which led to a new requirement for hyperspectral imaging (allowing for, e.g., derivative analyses that evaluate varying spectral properties of photosynthetic pigment absorption). Following additional design studies at GSFC, the OCEaNS concept was submitted as a white paper to the National Research Council Decadal Survey. The resulting Decadal Survey report ultimately recommended the fourinstrument Aerosol, Cloud, Ocean Ecosystems (ACE) mission, encompassing an ocean radiometer, aerosol lidar, polarimeter, and dual-frequency cloud radar (i.e., OCEaNS plus a cloud radar; National Research Council 2007).

ACE mission formulation activities supported 
a number of instrument design and mission studies, as well as the formation of working groups on oceans, aerosols, clouds, and ocean-atmosphere interactions-all tasked with submitting white papers on discipline science objectives and measurement requirements (e.g., ACE Ocean Working Group 2018). Over the course of ACE deliberations, a pre-ACE concept emerged where the two passive sensors (the ocean radiometer and polarimeter) would be launched

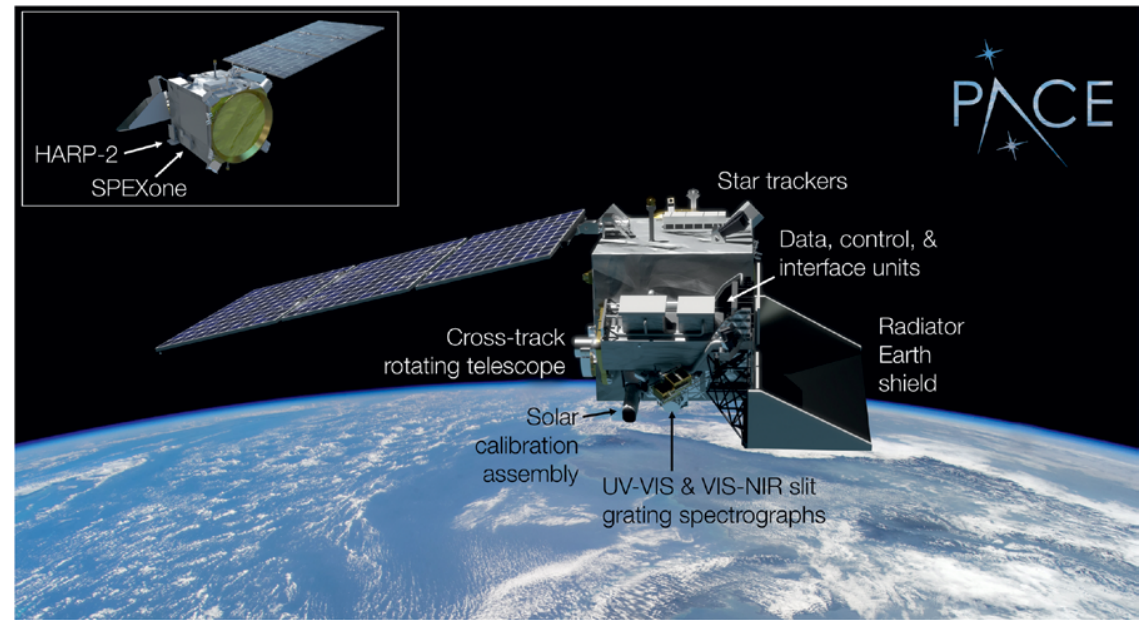

FIG. 3. The PACE observatory. Visible features of $\mathrm{OCI}$ (and spacecraft) identified in the main panel. The direction of flight is into the page. Placement of the two multiangle polarimeters shown in the inset, with the micrometeoroid orbital debris shield covering the propellant tank colored gold. earlier than the active sen-

sors (the lidar and radar). This cadence allowed costs for the full ACE mission to be spread in time, with the more developmentally mature, longer-lived passive sensors to be launched first, but still operating when the less mature, shorter-lived active sensors were launched. In 2010, NASA released a climate initiative document (NASA 2010) that, among other recommendations, called for a highly calibrated "ocean ecosystem spectroradiometer" comanifested with a multispectral and multiangle polarimeter. This announcement initialized the pre-ACE (conveniently shortened to PACE) mission and resulted in the formation of the PACE SDT, which convened from 2011 to 2012 (PACE Science Definition Team 2018). The SDT encompassed ocean, aerosol, cloud, and land disciplines and produced a report that ultimately codified the modern PACE mission science objectives. As will be elaborated upon later, NASA Headquarters directed GFSC to execute the PACE mission in 2015, requiring development of an advanced ocean color radiometer and encouraging acquisition of a multiangle polarimeter (Fig. 3). Fast forwarding to today, PACE represents a $\sim 20$-yr effort to formulate and design a next-generation ocean-atmosphere mission.

PACE SCIENCE. Oceans. Approximately half of the net photosynthetic production on Earth occurs in the ocean (Behrenfeld et al. 2001; Field et al. 1998). Amazingly, only $2 \%$ of the biosphere's plant biomass (i.e., phytoplankton) achieves this massive flux of carbon (i.e., the fixation of dissolved inorganic carbon into particulate organic carbon). This apparent contradiction exists because of the extremely rapid turnover of phytoplankton to other trophic levels. The entire global biomass of phytoplankton is produced and subsequently consumed every 2-6 days (Behrenfeld and Falkowski 1997). As a consequence, phytoplankton distributions rapidly register impacts of environmental change compared to, for example, grasslands or forests. The remotely detectable optical signal of phytoplankton, however, is very weak, even during periods of maximum abundance, and exacerbated by the fact that phytoplankton live in a strongly absorbing medium (water). This makes remote sensing observations of aquatic ecosystems among the most challenging in the Earth sciences. By contrast, the photosynthetic structures of terrestrial plants are large, have a strong optical signal, and are located in a weakly absorbing media (air). Rising to the challenge of global ocean remote sensing requires high precision instruments with high signal-to-noise measurements and detailed knowledge of atmospheric contributions to the measured top-of-atmosphere radiances (which are typically $>90 \%$ of the measured signal).

Heritage ocean color radiometers were designed to retrieve bulk aquatic properties, for example, near-surface concentrations of chlorophyll a and submarine light attenuation. These properties drive first-order variations in the spectral water-leaving reflectances calculated from the instrument-measured radiometry. The goals and approaches for heritage ocean color remote sensing have since been supplanted by far more ambitious science. Traditional algorithms to retrieve most bulk aquatic properties relate ratios of measured signals at two or more 
wave bands to the geophysical product of interest, an approach that mitigates some error in the radiometric calibration (e.g., O'Reilly et al. 1998). More contemporary algorithms, however, adopt spectral matching methods to simultaneously derive aquatic optical properties for multiple, independently varying aquatic properties, such as spectral absorption of phytoplankton pigments and colored dissolved organic material (CDOM) and spectral backscattering by particles (Garver and Siegel 1997; Roesler and Perry 1995; Werdell et al. 2018; and references therein). This is typically accomplished by assuming spectral shape functions for all aquatic constituent absorption and scattering components and using linear or nonlinear inversion methods to retrieve the magnitudes of each constituent required to match the spectral distribution of the water-leaving reflectance signal. Such spectral matching approaches remain, by default, sensitive to radiometric retrieval errors, as these errors are not mitigated through the use of ratios. Therefore, achieving PACE ocean science goals increases the demands on algorithm performance and, thus, the required accuracies of its derived waterleaving reflectances.

Analyses of heritage ocean color data records revealed that the interpretation of variations in bulk properties relies heavily on their more detailed underlying causes. Understanding these causative factors requires additional information, the acquisition of which provides a main driver in defining the measurement capabilities of PACE. For example, current ocean color records indicate that decreases in chlorophyll-a concentrations follow increases in ocean temperatures (e.g., Behrenfeld et al. 2006; Signorini et al. 2015). The meaning of these changes for ocean ecosystems, biogeochemistry, and human health and services, however, is not straightforward because changes in chlorophyll a can result from multiple factors that have different (and, in fact, opposite) implications. If decreases in phytoplankton biomass or increased nutrient stress cause a decrease in chlorophyll a, for example, then this decrease is associated with a reduction in photosynthesis and productivity. If increases in light caused by a (temperature related) shallowing of the surface mixed layer result in a decrease in chlorophyll a, however, then this decrease is associated with an elevation of photosynthesis and productivity. Deciphering these different effects can be accomplished by separately retrieving phytoplankton carbon and chlorophyll-a concentrations, then evaluating changes in chlorophyll-to-carbon ratios (Behrenfeld et al. 2016). This ratio, however, removes the first-order source of variability in ocean color data records (i.e., variations in biomass) and, thus, requires accurate retrieval of second-order factors that contain critical ecological information of interest. Retrieval of such factors, such as plankton community composition, places additional demands on the accuracy of PACE water-leaving reflectances and derived biogeochemical data products.

Phytoplankton community structure influences fisheries production, human health (e.g., as in the case of harmful or toxic algal blooms), and the efficiency of carbon and nutrient cycling (International Ocean-Colour Coordinating Group 2008, 2014) and, as such, understanding how phytoplankton communities change can be equally, if not more, important than how total chlorophyll-a or carbon stocks change. Remote sensing methods for identifying different phytoplankton groups exist (Bracher et al. 2017; Mouw et al. 2017), but again, these algorithms rely on accurate retrieval of second-order factors that influence ocean color, with the more advanced approaches also requiring hyperspectral measurements of at least 5-nm resolution (Lee et al. 2007; Vandermeulen et al. 2017; Fig. 2). Increased spectral resolution in the visible region greatly benefits both characterization of spectral phytoplankton pigment absorption, which is thought to be critical to improve estimates of net primary production (NPP), and spectral particulate backscattering, which offers new information on plankton size composition and metrics for the assessment of carbon stocks (Bracher et al. 2009; Catlett and Siegel 2018; Lubac et al. 2008; Torrecilla et al. 2011). Furthermore, accurate radiometric retrievals across the chlorophyll fluorescence region are essential to understand the various types of nutrient stress in global ocean phytoplankton, to provide an alternative assessment of phytoplankton pigments in optically complex waters, and to resume the chlorophyll fluorescence record initiated by MODIS. These critical scientific considerations all contribute to PACE observational requirements.

In addition to a hyperspectral capability, PACE objectives include the collection of ocean colorquality radiometric measurements in the ultraviolet (UV) region. Water-leaving reflectances from $\sim 350$ to $400 \mathrm{~nm}$ provide crucial (and currently missing) information for both accurately separating phytoplankton pigment absorption from CDOM absorption and for assessing the spectral slope of CDOM absorption, which can be related to its terrestrial and aquatic sources (Siegel et al. 2005, 2002). To put the importance of this separation into perspective, current assessments of global ocean annual NPP can differ by $>15 \mathrm{Pg} \mathrm{C} \mathrm{yr}^{-1}$ when based on chloro- 
phyll data derived from algorithms with different approaches to treating CDOM absorption (ACE Ocean Working Group 2018). Recognizing that total annual ocean production approaches $50 \mathrm{Pg} \mathrm{Cyr}^{-1}$, this CDOM-based uncertainty remains a major concern. UV measurements also provide critical input for the estimation of Raman scattering contributions to water-leaving reflectances and their subsequent removal in bio-optical models (e.g., McKinna et al. 2016). Furthermore, UV measurements provide additional information to improve upon heritage atmospheric correction processes. First, they will support development of improved absorbing aerosol identification methods. Without data from this spectral region, heritage instruments suffer from an inability to retrieve accurate water-leaving reflectances in geographic regions dominated by urban aerosols and dust (e.g., Gordon et al. 1997; Nobileau and Antoine 2005). In addition, UV water-leaving reflectances in productive waters generally fall near zero, providing potential additional constraints on the slope of the aerosol reflectance spectrum selected from the NIR and SWIR bands (Mobley et al. 2016).

Aerosols and clouds. The largest contributions of uncertainty to our understanding of Earth's climate are due to atmospheric aerosols, clouds, and the strong interactions between the two that have significant impacts on the distributions of radiative and latent heating of the atmosphere. Furthermore, the spatial and temporal distributions of aerosols and clouds are far more variable than that of greenhouse gases. Satellite-based remote sensing has therefore become an invaluable source of information about aerosols and clouds (Boucher et al. 2013). The total effective radiative forcing due to aerosols and their interactions with clouds (allowing for rapid adjustments to such forcing) are estimated with medium confidence to be $-0.9 \mathrm{~W} \mathrm{~m}^{-2}$, with an uncertainty estimate from -1.9 to $-0.1 \mathrm{~W} \mathrm{~m}^{-2}$ (Boucher et al. 2013). Thus, considerable uncertainty remains, which can be addressed with remote sensing measurements of improved accuracy and completeness (Mishchenko et al. 2004). In addition, long-term observations are critical for identifying climate-relevant trends (Mishchenko et al. 2007a), and, as such, heritage instruments with consistent capabilities are of particular value because they allow data records of adequate longevity to be acquired.

In recognition of this, the National Research Council Decadal Survey (National Research Council 2007) and NASA's climate initiative document (NASA 2010) called for a continuation of heritage observations to detect long-term trends, and the development of new remote sensing techniques with (passive) multiangle polarimeters and (active) lidars. As previously mentioned, early incarnations of the PACE mission recommended colocating passive instruments, such that the ocean color radiometer can continue heritage aerosol and cloud observations (such as those produced by MODIS and VIIRS; e.g., Hsu et al. 2013; Remer et al. 2005), and a multiangle polarimeter can provide a more accurate and complete understanding of aerosol and cloud states.

Aspects of a hyperspectral ocean color radiometer, as required for ocean remote sensing, offer promise for new techniques beyond aerosol and cloud heritage capabilities. Hyperspectral sensitivity from the UV through the visible spectrum will provide improved understanding of aerosol absorption and aerosols above clouds (de Graaf et al. 2007; Torres et al. 2007). This spectral range includes the $\mathrm{O}_{2} \mathrm{~A}$ band, which can be used to determine aerosol extinction vertical profiles, and thus constrain heights of aerosol layers (Corradini and Cervino 2006; Davis and Kalashnikova 2019; Dubuisson et al. 2009). New constraints on aerosol absorption and layer height are expected to lead to narrowing uncertainties in estimates of aerosol radiative forcing. Hyperspectral measurements through the $\mathrm{O}_{2} \mathrm{~A}$ band also offer information on cloud-top height (Desmons et al. 2013; Kokhanovsky et al. 2019; Vanbauce et al. 1998), which will be especially important for PACE, given that PACE does not collect measurements in the thermal infrared, the heritage spectral range used to characterize cloud macrophysical properties. SWIR channels will be used to continue characterization of cloud microphysical properties (e.g., Platnick et al. 2003), coarse-size mode aerosols (Tanré et al. 1997), and stratospheric aerosols (Gao and Kaufman 1995), and also to provide new methods of determining cloud thermodynamic phase (Coddington et al. 2017). Several papers summarizing the work of the first PACE Science Team (see below), and relevant to this topic, are currently in review in a special issue of Frontiers monographs (www.frontiersin.org /research-topics/7637/).

Justification for the inclusion of multiangle polarimetry was in part based on the studies supporting the Aerosol Polarimetry Sensor (APS) on the NASA Glory mission (Mishchenko et al. 2004, 2007b), which unfortunately failed at launch in 2011. Regardless, remote sensing with orbital multiangle polarimeters, such as the POLDER mission (Tanré et al. 1997), theoretical studies (Hasekamp and Landgraf 2007; Hasekamp et al. 2019; Knobelspiesse et al. 2012), and investigations with airborne prototypes (Cairns 2003; 
Cairns et al. 2003; Chowdhary et al. 2005; Gao et al. 2018; Knobelspiesse et al. 2011; Stamnes et al. 2018; Waquet et al. 2009) have shown that such instruments are capable of accurately retrieving aerosol microphysical properties such as size distribution, refractive index, absorption and morphology, which are important for identifying aerosol species and optical effects. Dubovik et al. (2019) present a comprehensive and recent review of multiangle polarimeter aerosol remote sensing. Additionally, these instruments have the capability to determine cloud optical properties in an entirely different, and therefore complementary, manner than heritage bispectral ratio approaches (Alexandrov et al. 2012; Miller et al. 2018).

As with ocean satellite remote sensing, heritage satellite radiometers have revolutionized our understanding the atmosphere. The ability to quantify atmospheric aerosol loading and characterize particle size, absorption (Torres et al. 2007), shape, and type (Kahn and Gaitley 2015) has enabled visualization of the global aerosol system (Kaufman et al. 2002), estimation of climate-scale aerosol radiative effects (Yu et al. 2006), and quantification of intercontinental aerosol transport (Yu et al. 2013). These capabilities further provide a source of information for air quality forecasting, mitigation, and policy (Al-Saadi et al. 2005; Hoff and Christopher 2009), and this will also be the case for PACE (Omar et al. 2018). Satellite radiometers that encompass the visible and thermal parts of the spectrum allow quantification of cloud microphysics, macrophysics, and cloud fraction (Frey et al. 2008; King et al. 2003; Platnick et al. 2003). This, in turn, has helped provide new understanding on the workings of the hydrological cycle (Benedict and Randall 2007; Koren et al. 2012), global-scale cloud parameter statistics (King et al. 2013), and insights into cloud processes from aerosol-cloud interaction to the climate scale (Kaufman et al. 2005; Meskhidze et al. 2009; Yuan et al. 2016). These observations, and the subsequent analysis, are the heritage that PACE must continue in the quest to identify long-term climate trends. Specific products are listed in Table 1, including spectral aerosol optical depth (AOD) over land and oceans, fraction of the AOD from fine-size mode particles (an indicator of aerosol size distribution), cloud-layer detection and thermodynamic phase identification, and the ability to determine cloud-top height, optical thickness, and the droplet effective radius. Beyond heritage, the full suite of aerosol optical properties (size distribution, refractive index, absorption) required for speciation and radiative forcing estimates will necessitate multiangle polarimeters to provide the requisite observational information content (PACE Science Team 2018). While data products from such instruments are not a requirement for the PACE mission, the existence of such instruments presents an exciting opportunity for aerosol and cloud science.

Science data products and interdisciplinary science. Assimilating and summarizing all of the above, pursuing PACE-era science objectives requires wellcharacterized, highly stable, and highly accurate passive hyperspectral radiometry and multispectral, multiangle polarimetry that spans the UV-to-NIR spectral range and further includes spectrally targeted broader-band measurements at longer NIR and SWIR wavelengths. These instruments must perform over a wide dynamic range of signal to enable science encompassing dark (ocean) and bright (cloud) science observables. While not listed in Table 1, PACE will produce a large suite of additional geophysical products from ocean color radiometry including, but not limited to, spectral aquatic inherent optical properties (e.g., absorption and scattering coefficients of seawater and its particulate and dissolved constituents), phytoplankton pigment concentrations, metrics related to phytoplankton physiology and carbon stocks, indices of absorbing aerosols, water paths for liquid and ice clouds, and data products to support land and applications studies (e.g., PACE Science Definition Team 2018). With regards to the latter, OCI's frequent, moderate-resolution, hyperspectral observations will complement Landsat's narrowswath, high-spatial-resolution, broad-spectral-band observations and also provide continuity with MODIS land products. It is expected that the mission will routinely produce terrestrial science data products, with potential applications of OCI data encompassing identification of structural and biochemical characteristics of plant canopies, evaluation of short-term and seasonal variations in diagnostic species, functional groups, and ecosystems, and description of global spatial patterns in biodiversity and ecosystem distributions. Inclusion of multiangle polarimetry on the observatory will enable production of additional data products, such as aerosol and hydrosol refractive indices and cloud bows, that further facilitate coupled ocean-atmosphere-land retrievals (e.g., PACE Science Team 2018).

Beyond the individual capabilities of any single instrument on the PACE observatory, the complement of measurement capabilities as a whole offers new and unprecedented opportunities for novel and interdisciplinary studies. Without question, OCI's capabilities for atmospheric retrievals, as well as the addition 
of two polarimeters, provides an additional wealth of information for use in ocean color atmospheric correction. And, the multiangle polarimetric measurements will allow production of sophisticated atmospheric (e.g., Alexandrov et al. 2012; Dubovik et al. 2019) and oceanic (e.g., Ibrahim et al. 2016; Loisel et al. 2008) science data products, as well as enable new coupled radiative transfer approaches to be realized (e.g., Gao et al. 2018; Stamnes et al. 2018). More broadly speaking, however, many core mission science objectives focus on the interaction of the atmosphere with the ocean's biological systems ("Core science objectives, questions, and applications" sidebar). In practice, the full suite of aerosol, cloud, and ocean color science data products enabled by the full PACE observatory will offer an extraordinary opportunity to improve our understanding of the interactions across and among atmospheric and oceanic constituents at the air-sea interface (e.g., Neukermans et al. 2018). Through the improved characterization and simultaneous collection of these derived products, PACE offers the chance to better reveal the distributions, sources, and sinks of atmospheric and oceanic constituents and how they ultimately interact and influence processes that govern Earth's radiative balance, the uptake and release of carbon by the ocean, and the sustainability of critical fisheries and aquatic ecosystems, to name only a few.

THE PACE OCI. OCI, the primary instrument in the PACE payload, is a hyperspectral imaging radiometer that combines design elements from SeaWiFS, MODIS, and VIIRS ("The PACE observatory" sidebar; Fig. 3). Its continuous coverage extends from 340 to $890 \mathrm{~nm}$ in the UV-to-NIR spectrum at 5-nm sampling and resolution and additionally includes seven discrete bands between 940 and 2,260 $\mathrm{nm}$ in the SWIR spectrum (Table 2). Like SeaWiFS, OCI will perform a tilt maneuver every orbit at approximately the subsolar point to avoid sun glint reflected off the ocean looking $20^{\circ}$ north (fore) in the Northern Hemisphere and $20^{\circ}$ south (aft) in the Southern Hemisphere, which maximizes the number of ocean science pixels retrieved (Fig. 4). As demonstrated by CZCS and SeaWiFS, tilting the radiometer allows capture of ocean science pixels that would otherwise be unusable because of sun glint contamination. The OCI telescope will scan from west to east at a rotation rate of $5.77 \mathrm{~Hz}$, acquiring Earth view data at a $1 \mathrm{~km} \times$ $1 \mathrm{~km}$ ground sample footprint at nadir and an angular range of $\pm 56.5^{\circ}$ for a ground swath width of $2,663 \mathrm{~km}$.

The OCI fore optics design follows that of SeaWiFS, with a rotating telescope, a half-angle mirror, and a transmissive depolarizer (rather than reflective one as with CZCS and SeaWiFS). Dichroics direct the light to three different focal planes: 1) a blue spectrograph (340-605 $\mathrm{nm}$; wavelength separation via grating and light detection via CCD), 2) a red spectrograph (600-890 nm; same approach as the blue spectrograph), and 3) a SWIR detection assembly (wavelength separation via dichroics and bandpass filters and light detection via photodiodes). While OCI will deliver 5-nm-sampled data from the two spectrographs in its default operating mode, it includes the capability for assembly of data at finer steps (e.g., $2.5 \mathrm{~nm}$ ), albeit 
with the same 5-nm bandwidth (Table 2) and increases in data volume. This capability may prove useful for limited studies of, for example, phytoplankton physiology and atmospheric gasses. Between 2008 and 2014, GSFC built a fully functional, but limited performance, test unit that included the fore optics and the two spectrographs (McClain et al. 2012). The SWIR detection assembly uses a new approach that guides light to individual detection units (InGaAs and $\mathrm{HgCdTe}$ photodiodes) through fiber optic cables. In summer 2019, a subset of SWIR bands and the red spectrograph will be evaluated as part of engineering test unit development in preparation for the OCI critical design review. In summer 2020, the flight unit that includes all spectral channels will be built.
Also like SeaWiFS, OCI uses time-delay integration (TDI) to increase its signal-to-noise ratios. Its instantaneous field of view is a rectangle sized $16 \mathrm{~km}$ $\times 1 \mathrm{~km}$ on the ground, with the long side of this rectangle in the scan direction. The readout rate of the CCD is synchronized with the telescope rotation such that the radiance from a $1 \mathrm{~km} \times 1 \mathrm{~km}$ area is read successively 16 times (=16:1 TDI). Accordingly, the total signal from a single $1 \mathrm{~km} \times 1 \mathrm{~km}$ ground pixel increases 16 -fold (compared to a single read) with a corresponding overall reduction in noise. The same principle is used for the SWIR bands, but the TDI varies from 2:1 to 8:1 for these discrete bands. SNR requirements for OCI range from 400 to 1,700 for the UV-NIR hyperspectral bands and

THE PACE OBSERVATORY

$D_{d}^{\text {es }}$ escribing the PACE observatory design in detail would require a volume of its own, but a brief overview will provide some context of the capability for gathering $\mathrm{OCl}$ and polarimeter data. The observatory, $\mathrm{OCl}$, and data product requirements assigned to the mission by NASA Headquarters largely mimic recommendations of the SDT. Required capabilities for multiangle polarimetry are not equally defined because this capability is not formally a requirement of the mission. Key requirements related to $\mathrm{OC}$ include

I) Earth surface spatial resolution of $\leq \mathrm{I} \pm 0 . \mathrm{I} \mathrm{km}^{2}$ at nadir for all bands;

2) 2-day global coverage to solar and sensor zenith angles of $75^{\circ}$ and $60^{\circ}$, respectively;

3) fore-aft instrument tilt to mitigate sun glint in the instrument field of view;

4) wavelengths from 340 to $890 \mathrm{~nm}$ at 5- \pm I-nm resolution;

5) additional wavelengths centered on $940,1,038,1,250,1,378,1,615$, 2,130 , and $2,260 \mathrm{~nm}$;

6) monthly lunar observations that illuminate all science detector elements;

7) daily instrument characterization [e.g., using solar diffusor(s)]; and

8) robust characterization of image artifacts and minimization of image striping.
A series of required data products with associated allowable uncertainties accompany the above (Table I). Measurement uncertainty allocations define instrument performance requirements, such as allowable random (e.g., signal to noise) and systematic (e.g., instrument linearity and temperature sensitivity) error. Additional requirements on the observatory include

9) 676.5-km altitude;

10) sun synchronous, polar, ascending orbit, with $98^{\circ}$ inclination;

II) I300 LT equatorial crossing; and

12) 3-yr design life with 10 years of propellant.

The PACE spacecraft is designed as a nonredundant "single string" architecture with selective redundancy based on evaluation of reliability, complexity, and cost. The major spacecraft subsystems that support the functions of the three PACE instruments include the following:

- Mechanical: Aluminum honeycomb construction designed to survive launch loads and support all components and instruments

- Thermal: Heaters, temperature sensors, and multilayer insulation and thermal coatings to keep all components within operational temperature requirements

- Guidance, navigation, and control: Star cameras, inertial reference units, GPS receiver, reaction wheels, a magnetometer, magnetic torque bars, and software algorithms to determine observatory position and control the observatory attitude

- Power: A solar array for power collection, a battery for energy storage during eclipse, and power system electronics for energy management and power distribution

- Avionics: Command and data handling electronics and flight software to command and control all observatory functions, including failure detection and correction

- Propulsion: A propellant tank, lines, valves, and thrusters to maintain the PACE orbit and to perform deorbit maneuvers at the end of mission for a safe ocean disposal

- Communications: Omnidirectional antennas and transponders for low rate S-band command and telemetry and a high-gain Earth coverage antenna and transmitter for highrate Ka-band science data transmission

- Mechanisms: Motors and actuators for launch lock restraints, solar array articulation, and performing the tilting function of the $\mathrm{OCl}$ instrument

These observatory components include a mixture of GSFC designs and vendor-procured units. GSFC designed and will test the observatory, including integration of the instruments. 
from 50 to 243 for the SWIR bands (Fig. 5) across an assigned dynamic range of radiances to be observed (i.e., the lowest expected ocean radiance to a maximum cloud radiance, defined as a Lambertian white cloud). OCI has 16-bit digitization to achieve the required radiance resolutions. Radiances used to study phytoplankton fluorescence require high SNRs (Behrenfeld et al. 2009), and, as such, the high end of the dynamic range for bands from 660 to $715 \mathrm{~nm}$ is reduced to $\sim 40 \%$ of the maximum cloud radiance, which results in a boost in SNR for these wavelengths. The 1,038-nm band is treated similarly to increase its SNR for use in ocean color atmospheric correction.

Ocean color data record development ultimately drives the design of OCI such that achieving calibration accuracies that mimic or improve upon SeaWiFS remains of principle concern during its development and operation (Zibordi et al. 2014). Sources of typical instrument uncertainties (e.g., sensitivity to polarization, stray light, and temperature) are addressed both by design choices and by a rigorous prelaunch test campaign, based largely on lessons learned from SeaWiFS, MODIS, and VIIRS heritage. Variations in the radiometric sensitivity of each channel over time are monitored by solar diffuser measurements for short-term instrument gain adjustments and independent lunar measurements for trend adjustments of long time periods ( 2 years or more).
The solar diffuser calibration assembly consists of three solar diffusers: two bright solar diffusers and one dim solar diffuser. The two bright solar diffusers are quasi-volume diffusers (QVD), selected because of their minimal degradation in the UV when exposed to solar irradiation as demonstrated by the

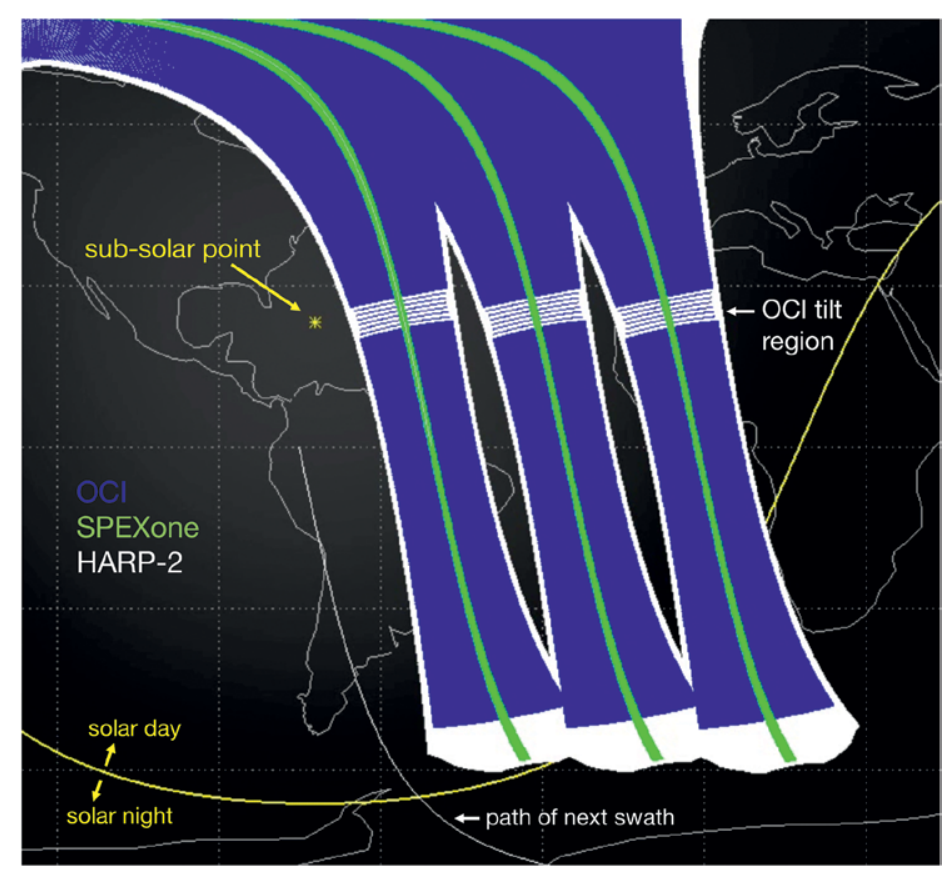

FIG. 4. Three example consecutive daytime orbits of the PACE observatory science data collection, showing the $\mathrm{OCI}$ (blue), SPEXone (green), and HARP-2 (white) swaths. The polarimeter swaths consider all along-track viewing angles (such that the HARP-2 swath width viewed at $\pm 57^{\circ}$ exceeds that of $\mathrm{OCl}$, which is $\pm 20^{\circ}$ ). The subsolar point and region of $\mathrm{OCl}$ aft-to-fore tilt are also shown.

\begin{tabular}{|c|c|c|c|}
\hline & OCl & HARP-2 & SPEXone \\
\hline $\begin{array}{l}\text { UV-NIR range } \\
\text { (bandwidth) }\end{array}$ & $\begin{array}{l}\text { Continuous from } 340 \text { to } 890 \mathrm{~nm}^{*} \\
\text { in } 5 \text {-nm steps (5) }\end{array}$ & $\begin{array}{l}440,550,670(10), \text { and } \\
870(40) \mathrm{nm}\end{array}$ & $\begin{array}{l}\text { Continuous from } 385 \text { to } \\
770 \mathrm{~nm} \text { in } 2-4-\mathrm{nm} \text { steps }\end{array}$ \\
\hline $\begin{array}{l}\text { SWIR range } \\
\text { (bandwidth) }\end{array}$ & $\begin{array}{l}940(45), \mathrm{I}, 038(75), \mathrm{I}, 250(30), \\
\mathrm{I}, 378(\mathrm{I}), \mathrm{I}, 6 \mathrm{I} 5(75), 2, \mathrm{I} 30(50) \\
\text { and } 2,260(75) \mathrm{nm}\end{array}$ & None & None \\
\hline Polarized bands & None & All & $\begin{array}{l}\text { Continuous from } 385 \text { to } \\
770 \mathrm{~nm} \text { in } 15-45-\mathrm{nm} \text { steps }\end{array}$ \\
\hline $\begin{array}{l}\text { Number of viewing } \\
\text { angles }\end{array}$ & $\begin{array}{l}\text { Fore-aft instrument tilt of } \pm 20^{\circ} \\
\text { to avoid sun glint }\end{array}$ & $\begin{array}{l}10 \text { for } 440,550 \text {, and } 870 \mathrm{~nm} \text { and } \\
\left.60 \text { for } 670 \mathrm{~nm} \text { (spaced over } 114^{\circ}\right)\end{array}$ & $5\left(-57^{\circ},-20^{\circ}, 0^{\circ}, 20^{\circ}, 57^{\circ}\right)$ \\
\hline Swath width & $\pm 56.5^{\circ}\left(2,663 \mathrm{~km}\right.$ at $20^{\circ}$ tilt $)$ & $\pm 47^{\circ}(\mathrm{I}, 556 \mathrm{~km}$ at nadir $)$ & $\pm 4^{\circ}$ (100 km at nadir) \\
\hline Global coverage & $\mathrm{I}-2+$ days & 2 days & $\sim 30$ days \\
\hline Ground pixel & $\mathrm{I} \mathrm{km}$ at nadir & $3 \mathrm{~km}$ & $2.5 \mathrm{~km}$ \\
\hline Institution & GSFC & UMBC & SRON \\
\hline
\end{tabular}

* The mission carries a goal of extending the shortest wavelength to $320 \mathrm{~nm}$.

+ There is 2-day coverage when limited to solar and sensor viewing angles of $75^{\circ}$ and $60^{\circ}$, respectively. 
Ozone Monitoring Instrument (OMI; Dobber et al. 2005). One bright diffuser will be measured daily by OCI to track short-term gain variations. The second bright diffuser will be measured monthly to determine the reflectance degradation of the daily solar diffuser. This approach is similar to that used by the Ozone Mapping and Profiler Suite (Seftor et al. 2014). Based on OMI data for its QVD, degradation of the daily solar diffuser could reach $\sim 7 \%$ at $350 \mathrm{~nm}$ after 3 years, but less so at longer wavelengths. The dim solar diffuser has a substantially lower reflectance $(\sim 2 \%)$ relative to the others. Using this dim diffusor, a special charge accumulation mode of the OCI CCDs will be used to verify the linearity of the OCI readout electronics and track changes in linearity over time. Essentially, OCI is able to measure exact multiples of the dim solar diffuser radiance, corresponding to measurements at reflectances of $2 \%$, $4 \%, 6 \%$, and so on, to enable the calculation of a linearity curve. This novel approach was not possible for heritage sensors.

Lunar measurements will be acquired by special spacecraft maneuvers that occur twice every lunar month at lunar phase angles of $\pm 7^{\circ}$ (representing a waxing and waning moon, respectively). This approach for monitoring on-orbit relative sensor spectral stability was first demonstrated with SeaWiFS (Eplee et al. 2012) and has been since shown to be the most robust method for long-term stability monitoring of ocean color radiometers (Zibordi et al. 2014). The PACE spacecraft will direct the OCI line of sight away from Earth toward the moon, enabling OCI to acquire two full images of the moon in two separate sweeps for each maneuver. The measured lunar irradiances will be compared to the Robotic Lunar Observatory (ROLO) model (Kieffer and Stone 2005) after calibration with the gain coefficients derived from the solar diffuser measurements and any derived trends will be corrected using the approach described in Eplee et al. (2015) for the calibration of VIIRS.

\section{THE PACE MULTIANGLE POLARIMETERS.}

While highly desirable from a scientific perspective, inclusion of a multiangle polarimeter on the PACE observatory was not included in the requirements levied on the mission. In a divergence from the SDT recommendation, NASA Headquarters designated polarimetry as optional, not required for PACE. Following this designation, when exploring options for acquiring polarimetry, the PACE project and NASA Headquarters conceived of a desired instrument architecture with value to the mission in quite general terms. This provided flexibility in obtaining the desired measurement capability within mission cost and schedule constraints without in any way prescribing a particular design. Essential instrument characteristics included 1) four or more spectral bands between 400 and $1,600 \mathrm{~nm}$, 2) four or more viewing angles over $a \pm 50^{\circ}$ view-angle range from nadir, 3) an uncertainty in the degree of linear polarization of $<0.01$, and 4 ) and a swath width of at least $\pm 15^{\circ}$. For reference, the latter enables aerosol characterization for atmospheric correction of OCI over $\sim 27 \%$ of its swath width. Ultimately, two

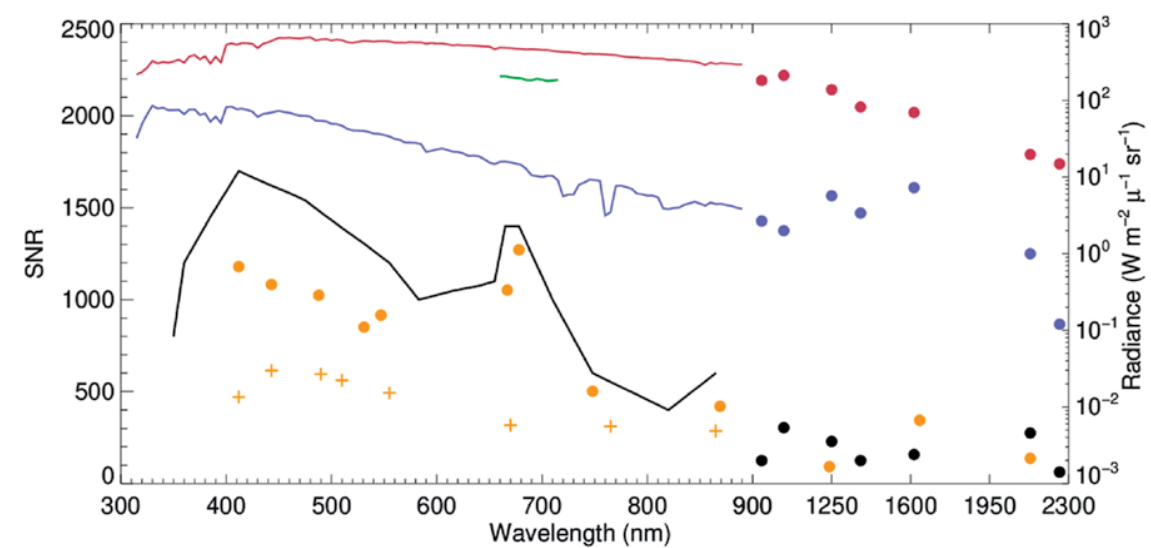

FIG. 5. The OCI SNR requirement (black; left axis) and the corresponding typical ocean (blue; right axis) and maximum cloud (red; right axis) radiances used in the derivation of the SNRs (with the exception of I,378- and 2,130-nm typical radiances, which represent values for clouds). For wavelengths less than $900 \mathrm{~nm}$, SNRs are presented for 15-nm aggregations around 350, 360, $385,412,425,443,460,475,490,510,532,555,583,617,640,655,710$, and $820 \mathrm{~nm}$, for $10-\mathrm{nm}$ aggregations around 665,678 , and $748 \mathrm{~nm}$, and for a $40-\mathrm{nm}$ aggregation around $865 \mathrm{~nm}$. This aggregation of UV-NIR radiometry will be distributed by the mission, as well as the native $5-\mathrm{nm}$ radiometry. The green line shows the $\sim 40 \%$ reduction in maximum radiance adopted to elevate SNRs in the phytoplankton fluorescence spectral region. While calculated differently than for OCI, SNRs for MODIS Aqua (orange circles; left axis) and SeaWiFS (orange crosses; left axis) are shown for general context. The MODIS Aqua and SeaWiFS visible-NIR SNRs are those derived postlaunch by Hu et al. (20I2) and the MODIS Aqua SWIR SNRs are the mission requirements presented in Xiong et al. (2010). 
contributed polarimeters are included on the PACE observatory-the Spectro-polarimeter for Planetary Exploration (SPEXone) and the Hyper Angular Research Polarimeter (HARP-2) - both carrying a "do no harm" designation, which prohibits disturbing the primary instrument (OCI) or levying additional requirements on the remainder of the observatory (Fig. 3). Despite this, SPEXone and HARP-2 jointly achieve the desired observations by providing complementary spectral and angular sampling, polarimetric accuracy, and spatial coverage (Table 2; Fig. 4). These observations will provide opportunities for improved OCI atmospheric corrections and a comprehensive range of aerosol and cloud science data products beyond what can be achieved with OCI alone.

The SPEXone instrument is one of a family of SPEX instruments that use a spectral modulation technique for determining the polarization state of reflected sunlight (Hasekamp et al. 2019; van Amerongen 2018). It is being developed by a Netherlands-based consortium consisting of the Space Research Organization of the Netherlands (SRON) and Airbus Defense and Space Netherlands. Encoding the degree and angle of linear polarization into a modulation of the radiance spectrum is the key characteristic of this concept (Snik et al. 2009). While small (compatible with a $12 \mathrm{U}$ Cubesat), SPEXone focuses specifically on providing very high polarimetric accuracy in measurements from the nearultraviolet to the near-infrared at 2-4-nm spectral resolution for intensity and $15-45-\mathrm{nm}$ resolution for degree and angle of linear polarization at five viewing angles spaced over $\pm 57^{\circ}$ from nadir (Table 2). Its characteristics allow for unprecedented space-based characterization of aerosol absorption and composition through estimation of complex refractive indices (e.g., Hasekamp and Landgraf 2007).

The HARP-2 instrument builds on heritage from a Cubesat instrument built for the NASA Invest Program by the Earth and Space Institute at the University of Maryland, Baltimore County (Martins 2017; Martins et al. 2018). It is a hyperangular imaging polarimeter that will see Earth simultaneously from multiple viewing angles at four wavelengths and three polarization states (Table 2). The HARP-2 concept builds on a modified Philips prism design that allows for simultaneous measurements of the complete image analyzed by polarizers in three different orientations (FernandezBorda et al. 2009). The different along-track viewing angles provided by its wide field of view allow observations of targets on the ground from different viewing perspectives, including up to 60 independent angles at $670 \mathrm{~nm}$ and up to 20 different viewing angles at the other three wavelengths (Table 2). The different viewing observations of the same target, with polarization measurements for all bands and view angles, facilitate the quantitative retrieval of atmospheric and surface properties such as aerosol particle abundances, aerosol particle sizes, shape and complex refractive indices, as well as cloud droplet sizes, ice particle shapes and roughnesses, and characteristics of Earth's surface.

Individually, the SPEXone and HARP-2 concepts excel at the retrieval of different atmospheric properties. Jointly, however, the instrument pair achieves desired PACE mission objectives by providing complementary spectral and angular sampling and spatial coverage. Summarizing the above, SPEXone provides high-spectral-resolution data that includes the UV, offering critical information to advance aerosol characterization and ocean color atmospheric correction. The utility of the latter to support OCI, however, remains limited given its narrow swath. HARP-2 provides hyperangular data that will enable improved retrievals of cloud droplet size and ice particle shape and roughness. Its broad swath complements OCI, but at a far more limited spectral resolution than SPEXone. Both polarimeters will advance the observatory capabilities beyond what can be accomplished with OCI alone and offer far greater information content than any heritage passive system for ocean color, aerosol, and cloud observations.

\section{PUTTING IT ALL TOGETHER: MISSION FORMULATION AND PROGRAMMATICS.}

In January 2015, NASA Headquarters directed Goddard Space Flight Center (GFSC) to execute the PACE mission ("The PACE observatory" sidebar). The scope of this direction included overall mission management (e.g., budget and schedule), acquisition of the spacecraft and launch vehicle, integration and testing of all mission elements, mission operations and ground systems, development of an imaging radiometer for oceanic and atmospheric applications, acquisition of the optional polarimeter(s), and science data processing. Headquarters specifically assigned ocean and atmosphere science data processing to the GSFC Ocean Biology Processing Group (OBPG; https://oceancolor.gsfc.nasa.gov), the entity currently responsible for processing and distribution of all ocean color data under NASA auspices. NASA Headquarters allocated a not-to-be-exceeded ("design to cost") $\$ 805$ million to the mission to be managed by GSFC and the Earth Science Division (ESD) at headquarters to support all the elements listed above, as well as acquisition and deployment of a vicarious calibration instrument system, development of a 
postlaunch validation program, and assembly of all competed community science teams.

The "design to cost" paradigm imposed on PACE means that the mission aims to maximize science capabilities within a stringently fixed budget. The project conducted a long series of early mission formulation studies to determine the maximum science capabilities above the assigned requirements ("The PACE observatory" sidebar) that were allowable within mission cost and schedule (NASA 2018a,b,c). Definition of desired, yet achievable, science capabilities focused on consideration of the core PACE science objectives and questions outlined by the SDT, the first science team, and NASA Headquarters. Societal, economic, and applied science considerations were also embedded in mission formulation studies (Omar et al. 2018), with the expectation that PACE data products will provide significant societal benefits and contribute to multiple applications that aid natural resource managers, policymakers, military users, government agencies, economists, and nongovernmental organizations ("Core science objectives, questions, and applications" sidebar). All of these factors and considerations ultimately led to the PACE mission science and measurement objectives encapsulated in this manuscript.

\section{COMMUNITY INVOLVEMENT: THE FIRST SCIENCE TEAMS AND LIFE AFTER}

LAUNCH. Opportunities for community involvement persisted following the dissolution of the SDT. In 2014, NASA assembled the first PACE Science Team to address two core topics: 1) ocean color atmospheric correction and the retrieval of atmospheric data products and 2) retrieval of improved aquatic spectral inherent optical properties (IOPs; Boss and Remer 2018). This science team produced a series of consensus documents on mission polarimetry (PACE Science Team 2018), cloud retrievals (Platnick et al. 2018), and IOP retrievals (Werdell et al. 2018). The team also produced a special issue of Frontiers monographs (www.frontiersin.org /research-topics/7637/) on ocean color atmospheric corrections and the retrieval of atmospheric properties using capabilities of the PACE observatory.

In 2014, NASA also sought ways to provide or develop in situ vicarious calibration instruments, systems, and approaches for the mission's ocean color instrument. Producing geophysical data products of sufficient quality to meet PACE science objectives depends fundamentally on the quality of radiometric data collected by the sensor. This, in turn, requires stringent calibration and validation for quantifying instrument performance, monitoring instrument stability, and satisfying uncertainty requirements of the radiometric retrievals (including a "vicarious" calibration for final bias adjustment to the calibrated, spectral top-of-atmosphere radiances observed by the satellite instrument; Franz et al. 2007). NASA selected three projects to begin development of new instrumentation and approaches for PACE vicarious calibration. The first focused on development of hyperspectral radiometers on autonomous buoys (Barnard et al. 2018). The second explored wave glider technology for autonomous deployment of a profiling radiometer. The third involved the evolution of the existing Marine Optical Buoy (MOBY; Clark et al. 1997), with a focus on technology that was portable and shippable. These projects concluded in 2018; however, a second round of competition to select the at-launch system for PACE vicarious calibration was released in 2019.

The PACE mission includes a (to-be-developed and/or competed) postlaunch validation program to verify that the required ocean color, aerosol, and cloud science data products from OCI meet the specified mission requirements (Table 1). This program will also strive to validate advanced science data products derived from OCI, HARP-2, and SPEXone, quantify uncertainties associated with each data product, and evaluate how these uncertainties vary across ocean water types, cloud properties, and aerosol loading and composition conditions. Customarily, validation of satellite data products has been accomplished by comparing satellite data with measurements collected in situ and through airborne or remote sensing platforms (e.g., another satellite sensor or instrumented system on Earth's surface). The validation analysis involves comprehensive statistical comparisons of field measurements (in situ or remotely sensed) that are coincident with the satellite data products to determine the uncertainties or deviations between the field measurements and satellite-derived data products. An essential element for any such validation analysis is that the uncertainties of the field measurements must be well understood and quantifiable. This requires development, maintenance, and strict adherence to community-accepted field measurement protocols that describe proper traceability to fiducial references from national metrology institutions such as the National Institute of Standards and Technology (NIST), as first demonstrated during the SeaWiFS era (Mueller et al. 2003). In lieu of field measurements (aircraft, ship, ground), which may prove elusive for certain PACE aerosol and cloud products, validation of these PACE data products may be accomplished with previously validated products produced from 
other satellite sensors (e.g., VIIRS). It is expected that dedicated team(s) will be assembled to perform matchup validation analyses of available field measurements with PACE-derived science data products using peer-reviewed metrics and software tools.

Potential sources of field measurements for PACE science data product validation include PACE-funded field activities, measurements provided by existing infrastructure that will presumably continue, and data obtained from existing or planned external resources implemented by other agencies. The mission envisions a competed PACE Validation Science Team (PVST) to be tasked with collecting field measurements at sufficient quality, range of environmental conditions, dynamic range, and geographic distribution to enable validation and to estimate uncertainties of PACE science data products. PACE-funded activities may include a dedicated aircraft and oceanographic ship field campaign within months of launch and a range of cost-effective approaches such as deployment of a fleet of small autonomous vehicles, measurements from repeatable field outings, enhancing existing measurement stations/sites, and field campaigns of opportunity. Existing NASA infrastructure that PACE can utilize for validation of ocean color, aerosol, and cloud products include the Aerosol Robotic Network for Ocean Color (AERONET-OC; Zibordi et al. 2009), AERONET (Holben et al. 1998), the Marine Aerosol Network (Smirnov et al. 2009), and ground-based radar and ceilometers.

Knowledge, modeling, and measurement gaps unavoidably exist (e.g., see the PACE Science Team IOP gaps matrix; https://pace.oceansciences.org/docs (pace_gaps_iop.pdf) and careful attention to these issues will be important to maximize the success of the PACE mission. Gaps include, but are not limited to, the need for 1) additional field measurements and campaigns that encompass the full suite of oceanic and atmospheric capabilities of the PACE observatory; 2) new in situ and laboratory instrumentation that matches the capabilities of OCI and the polarimeters; 3) improved measurements and understanding of the optical effects of aquatic and atmospheric constituents in the UV; 4) increased development and accessibility of radiative transfer software that considers all processes (e.g., inelastic scattering and polarization) and more realistic models of particles with coatings and irregular shapes; 5 ) continued improvement of bio-optical (including characterization of pure seawater), aerosol, and surface models; and 6) development and maintenance of a full suite of community consensus protocols for all relevant in situ and laboratory measurements.
ENABLING THE NEXT GENERATION OF EARTH SYSTEM SCIENTISTS. The PACE mission emerged from a near two-decade-long science community effort aimed at not only bringing satellite ocean color measurement capability up to speed with science capabilities and needs, but also providing data records of the Earth system that the next generation of scientist can grow into. The PACE mission concept encompasses needs for ocean color, aerosol, and cloud observations and, importantly, envisions synergistic opportunities between these science communities. Such synergy increases many times over given an increasing number of opportunities for multi- and interdisciplinary field campaigns, such as the NASA Export Processes in the Ocean from Remote Sensing (EXPORTS; Siegel et al. 2016) and North Atlantic Aerosols and Marine Ecosystems Study (NAAMES; Behrenfeld et al. 2019) activities. Key elements of the PACE mission include an imaging radiometer providing the first continuously collected global hyperspectral data of sufficient quality for advanced ocean ecosystem retrieval and the comanifestation of two multiangle polarimeters for aerosol and cloud remote sensing, as well as ocean color atmospheric correction and improved identification of subsurface marine particles and plankton. In combination, the hyperspectral, broad-swath radiometric measurements from OCI (ranging from the UV to SWIR wavelengths), the hyperangular measurements from HARP-2, and the hyperspectral measurements from SPEXone substantially increase science value of the mission beyond what could be available from any one measurement or a single-sensor mission.

ACKNOWLEDGMENTS. Many thanks to all who have contributed to the conception, formulation, and realization of the PACE mission. Additional thanks to the instrument, spacecraft, and ground system teams, to staff within the Ocean Biology Processing Group, and to the science teams for their endless enthusiasm and dedication to this mission. Thank you also to David Siegel and one anonymous reviewer for their thoughtful and conscientious review of this manuscript.

\section{REFERENCES}

ACE Ocean Working Group, 2018: ACE Ocean Working Group recommendations and instrument requirements for an advanced ocean ecology mission. PACE Tech. Rep. NASA/TM-2018-219027, Vol. 1, 48 pp.

Alexandrov, M. D., B. Cairns, C. Emde, A. S. Ackerman, and B. van Diedenhoven, 2012: Accuracy assessment of cloud droplet size retrievals from polarized 
reflectance measurements by the research scanning polarimeter. Remote Sens. Environ., 125, 92-111, https://doi.org/10.1016/j.rse.2012.07.012.

Al-Saadi, J., and Coauthors, 2005: Improving national air quality forecasts with satellite aerosol observations. Bull. Amer. Meteor. Soc., 86, 1249-1262, https:// doi.org/10.1175/BAMS-86-9-1249.

Barnard, A., and Coauthors, 2018: A new paradigm for ocean color satellite calibration and validation: Accurate measurements of hyperspectral water leaving radiance from autonomous profiling floats (HYPERNAV). Earth and Space Science Open Archive, https://doi.org/10.1002/essoar.10500047.1.

Behrenfeld, M. J., and P. G. Falkowski, 1997: Photosynthetic rates derived from satellite-based chlorophyll concentration. Limnol. Oceanogr., 42, 1-20, https:// doi.org/10.4319/lo.1997.42.1.0001.

— , and Coauthors, 2001: Biospheric primary production during an ENSO transition. Science, 291, 2594-2597, https://doi.org/10.1126/science.1055071.

— , and Coauthors, 2006: Climate-driven trends in contemporary ocean productivity. Nature, 444, 752-755, https://doi.org/10.1038/nature05317.

_ , and Coauthors, 2009: Satellite-detected fluorescence reveals global physiology of ocean phytoplankton. Biogeosciences, 6, 779-794, https:/doi .org/10.5194/bg-6-779-2009.

— , and Coauthors, 2016: Revaluating ocean warming impacts on global phytoplankton. Nat. Climate Change, 6, 323-330, https://doi.org/10.1038 /nclimate2838.

—_ and Coauthors, 2019: The North Atlantic Aerosol and Marine Ecosystem Study (NAAMES): Science motive and mission overview. Front. Mar. Sci., 22, 122, https://doi.org/10.3389/fmars.2019.00122.

Benedict, J. J., and D. A. Randall, 2007: Observed characteristics of the MJO relative to maximum rainfall. J. Atmos. Sci., 64, 2332-2354, https://doi.org/10.1175 /JAS3968.1.

Boss, E., and L. A. Remer, 2018: A novel approach to a satellite mission's science team. Eos, Trans. Amer. Geophys. Union, 99, https://doi.org/10.1029/2018EO092639.

Boucher, O., and Coauthors, 2013: Clouds and aerosols. Climate Change 2013: The Physical Science Basis, T. F. Stocker et al., Eds., Cambridge University Press, 571-657.

Bracher, A., M. Vountas, T. Dinter, J. P. Burrows, R. Rottgers, and I. Peeken, 2009: Quantitative observation of cyanobacteria and diatoms from space using PhytoDOAS on SCIAMACHY data. Biogeosciences, 6, 751-764, https://doi.org/10.5194/bg-6-751-2009.

_ , and Coauthors, 2017: Obtaining phytoplankton diversity from ocean color: A scientific roadmap for future development. Front. Mar. Sci., 4, 55, https:// doi.org/10.3389/fmars.2017.00055.

Cairns, B., 2003: Polarimetric remote sensing of aerosols. Proc. IEEE Int. Geoscience and Remote Sensing Symp., Toulouse, France, Institute of Electrical and Electronics Engineers, 518-520, https://doi .org/10.1109/IGARSS.2003.1293828.

— E. E. Russell, J. D. LaVeigne, and P. M. Tennant, 2003: Research scanning polarimeter and airborne usage for remote sensing of aerosols. Proc. SPIE, 5158, 33-45, https://doi.org/10.1117/12.518320.

Catlett, D., and D. A. Siegel, 2018: Phytoplankton pigment communities can be modeled using unique relationships with spectral absorption signatures in a dynamic coastal environment. $J$. Geophys. Res. Oceans, 123, 246-264, https://doi .org/10.1002/2017JC013195.

Chowdhary, J., B. Cairns, M. I. Mishschenko, and L. D. Travis, 2005: Using multi-angle multispectral photo-polarimetry of the NASA Glory mission to constrain optical properties of aerosols and clouds: Results from four field experiments. Proc. SPIE, 5978, 59780G, https://doi.org/10.1117/12.631201.

Clark, D. K., H. R. Gordon, K. J. Voss, Y. Ge, W. W. Broenkow, and C. Trees, 1997: Validation of atmospheric correction over the oceans. J. Geophys. Res., 102, 17209-17217, https://doi.org/10.1029/96JD03345.

Coddington, O. M., T. Vukicevic, K. S. Schmidt, and S. Platnick, 2017: Characterizing the information content of cloud thermodynamic phase retrievals from the notional PACE OCI shortwave reflectance measurements. J. Geophys. Res. Atmos., 122, 8079-8100, https://doi.org/10.1002/2017JD026493.

Corradini, S., and M. Cervino, 2006: Aerosol extinction coefficient profile retrieval in the oxygen-A band considering multiple scattering atmospheres. J. Quant. Spectrosc. Radiat. Transfer, 97, 354-380, https://doi.org/10.1016/j.jqsrt.2005.05.061.

Costantino, L., and F. M. Breon, 2010: Analysis of aerosol-cloud interaction from multi-sensor satellite observations. Geophys. Res. Lett., 37, L11801, https:// doi.org/10.1029/2009GL041828.

Davis, A. B., and O. V. Kalashnikova, 2019: Aerosol layer height over water via oxygen A-band observations from space: A tutorial. Radiative Transfer and Light Scattering, A. Kokhanovsky, Ed., Springer Series in Light Scattering, Vol. 3, Springer, 133-166.

de Graaf, M., P. Stammes, and E. A. A. Aben, 2007: Analysis of reflectance spectra of UV-absorbing aerosol scenes measured by SCIAMACHY. J. Geophys. Res., 112, D02206, https://doi.org/10.1029/2006JD007249.

Desmons, M., N. Ferlay, F. Parol, L. Mcharek, and C. Vanbauce, 2013: Improved information about the 
vertical location and extent of mono-layer clouds from POLDER3 measurements in the oxygen A-band. Atmos. Meas. Tech., 6, 2221-2238, https://doi .org/10.5194/amt-6-2221-2013.

Dobber, M., and Coauthors, 2005: Ozone Monitoring Instrument in-flight performance and calibration. Proc. SPIE, 5962, 59621L, https://doi .org/10.1117/12.624212.

Dubovik, O., and Coauthors, 2019: Polarimetric remote sensing of atmospheric aerosols: Instruments, methodologies, results, and perspectives. J. Quant. Spectrosc. Radiat. Transfer, 224, 474-511, https://doi .org/10.1016/j.jqsrt.2018.11.024.

Dubuisson, P., R. Frouin, D. Dessailly, L. Duforêt, J. F. Leon, K. Voss, and D. Antoine, 2009: Estimating the altitude of aerosol plumes over the ocean from reflectance ratio measurements in the $\mathrm{O}_{2}$ A-band. Remote Sens. Environ., 113, 1899-1911, https://doi .org/10.1016/j.rse.2009.04.018.

Eplee, R. E., G. Meister, F. S. Patt, B. A. Franz, S. W. Bailey, and C. R. McClain, 2012: On-orbit calibration of SeaWiFS. Appl. Opt., 51, 8702-8370, https://doi .org/10.1364/AO.51.008702.

_, K. R. Turpie, G. Meister, F. S. Patt, B. A. Franz, and S. W. Bailey, 2015: On-orbit calibration of the Suomi National Polar-Orbiting Partnership Visible Infrared Imaging Radiometer Suite for ocean color applications. Appl. Opt., 54, 1984-2006, https://doi .org/10.1364/AO.54.001984.

Fernandez-Borda, R., E. Walushka, S. Pellicori, J. V. Martins, L. Ramos-Izquierda, J. D. Cieslak, and P. Thompson, 2009: Evaluation of the polarization properties of a Philips-type prism for the construction of imaging polarimeters. Proc. SPIE, 7461, 746113, https://doi.org/10.1117/12.829080.

Field, C. B., M. J. Behrenfeld, J. T. Randerson, and P. Falkowski, 1998: Primary production of the biosphere: Integrating terrestrial and oceanic components. Science, 281, 237-240, https://doi.org/10.1126 /science.281.5374.237.

Franz, B. A., S. W. Bailey, P. J. Werdell, and C. R. McClain, 2007: Sensor-independent approach to the vicarious calibration of satellite ocean color radiometry. Appl. Opt., 46, 5068-5082, https://doi .org/10.1364/AO.46.005068.

Frey, R. A., S. A. Ackerman, Y. H. Liu, K. I. Strabala, H. Zhang, J. R. Key, and X. G. Wang, 2008: Cloud detection with MODIS. Part I: Improvements in the MODIS cloud mask for collection 5. J. Atmos. Oceanic Technol., 25, 1057-1072, https://doi .org/10.1175/2008JTECHA1052.1.

Gao, B. C., and Y. J. Kaufman, 1995: Selection of the 1.375- $\mu \mathrm{m}$ MODIS channel for remote sensing of cirrus clouds and stratospheric aerosols from space. J. Atmos. Sci., 52, 4231-4237, https://doi .org/10.1175/1520-0469(1995)052<4231:SOTMCF $>2.0 . \mathrm{CO} ; 2$.

Gao, M., and Coauthors, 2018: Retrieval of aerosol properties and water-leaving reflectance from multiangular polarimetric measurements over coastal waters. Opt. Express, 26, 8968-8989, https://doi .org/10.1364/OE.26.008968.

Garver, S. A., and D. A. Siegel, 1997: Inherent optical property inversion of ocean color spectra and its biogeochemical interpretation 1. Time series from the Sargasso Sea. J. Geophys. Res., 102, 18607-18625, https://doi.org/10.1029/96JC03243.

Gordon, H. R., T. Du, and T. Zhang, 1997: Remote sensing of ocean color and aerosol properties: Resolving the issue of aerosol absorption. Appl. Opt., 36, 8670-8684, https://doi.org/10.1364/AO.36.008670.

Hasekamp, O. P., and J. Landgraf, 2007: Retrieval of aerosol properties over land surfaces: Capabilities of multiple-viewing-angle intensity and polarization measurements. Appl. Opt., 46, 3332-3344, https://doi .org/10.1364/AO.46.003332.

— SPEXone on the NASA PACE mission: Expected retrieval capabilities. J. Quant. Spectrosc. Radiat. Transfer, 227, 170-184, https://doi.org/10.1016/j .jqsrt.2019.02.006.

Hoff, R. M., and S. A. Christopher, 2009: Remote sensing of particulate pollution from space: Have we reached the promised land? J. Air Waste Manage. Assoc., 59, 645-675, https://doi.org/10.3155/1047-3289.59.6.645.

Holben, B. N., and Coauthors, 1998: AERONET-A federated instrument network and data archive for aerosol characterization. Remote Sens. Environ., 66, 1-16, https://doi.org/10.1016/S0034-4257(98)00031-5.

Hsu, N. C., M.-J. Jeong, C. Bettenhausen, A. M. Sayer, R. Hansell, C. S. Seftor, J. Huang, and S.-C. Tsay, 2013: Enhanced Deep Blue aerosol retrieval algorithm: The second generation. J. Geophys. Res. Atmos., 118, 9296-9315, https://doi.org/10.1002/jgrd.50712.

Hu, C. M., L. Feng, Z. Lee, C. O. Davis, A. Mannino, C. R. McClain, and B. A. Franz, 2012: Dynamic range and sensitivity requirements of satellite ocean color sensors: Learning from the past. Appl. Opt., 51, 6045-6062, https://doi.org/10.1364/AO.51.006045.

Ibrahim, A., A. Gilerson, J. Chowdhary, and S. Ahmed, 2016: Retrieval of macro- and micro-physical properties of oceanic hydrosols from polarimetric observations. Remote Sens. Environ., 186, 548-566, https://doi.org/10.1016/j.rse.2016.09.004.

International Ocean-Colour Coordinating Group, 2008: Why ocean colour? The societal benefits of ocean- 
colour technology. International Ocean-Colour Coordinating Group Rep. 7, 147 pp.

_ 2014: Phytoplankton functional types from space. International Ocean-Colour Coordinating Group Rep. 15, 164 pp.

Kahn, R. A., and B. J. Gaitley, 2015: An analysis of global aerosol type as retrieved by MISR. J. Geophys. Res. Atmos., 120, 4248-4281, https://doi.org /10.1002/2015JD023322.

Kaufman, Y. J., D. Tanré, and O. Boucher, 2002: A satellite view of aerosols in the climate system. Nature, 419, 215-223, https://doi.org/10.1038/nature01091.

—, I. Koren, L. A. Remer, D. Rosenfeld, and Y. Rudich, 2005: The effect of smoke, dust, and pollution aerosol on shallow cloud development over the Atlantic Ocean. Proc. Natl. Acad. Sci. USA, 102, 11 207-11212, https://doi.org/10.1073/pnas.0505191102.

Kieffer, H. H., and T. C. Stone, 2005: The spectral irradiance of the moon. Astron. J., 129, 2887-2901, https:// doi.org/10.1086/430185.

King, M. D., and Coauthors, 2003: Cloud and aerosol properties, precipitable water, and profiles of temperature and water vapor from MODIS. IEEE Trans. Geosci. Remote Sens., 41, 442-458, https://doi .org/10.1109/TGRS.2002.808226.

—, S. Platnick, W. P. Menzel, S. A. Ackerman, and P. A. Hubanks, 2013: Spatial and temporal distribution of clouds observed by MODIS onboard the Terra and Aqua satellites. IEEE Trans. Geosci. Remote Sens., 51, 3826-3852, https://doi.org/10.1109 /TGRS.2012.2227333.

Knobelspiesse, K., B. Cairns, J. Redemann, R. W. Bergstrom, and A. Stohl, 2011: Simultaneous retrieval of aerosol and cloud properties during the MILAGRO field campaign. Atmos. Chem. Phys., 11, 6245-62 643, https://doi.org/10.5194/acp-11-6245-2011.

— , and Coauthors, 2012: Analysis of fine-mode aerosol retrieval capabilities by different passive remote sensing instrument designs. Opt. Express, 20, 21 457-21 484, https://doi.org/10.1364/OE.20.021457.

Kokhanovsky, A. A., L. Lelli, F. Ducos, and R. Munro, 2019: A simple approximation for the reflectance of a thick cloud in gaseous absorption band and its application for the cloud-top height determination. IEEE Trans. Geosci. Remote Sens., 57, 3324-3330, https://doi.org/10.1109/TGRS.2018.2883358.

Koren, I., O. Altaratz, L. A. Remer, G. Feingold, J. V. Martins, and R. H. Heiblum, 2012: Aerosol-induced intensification of rain from the tropics to the mid-latitudes. Nat. Geosci., 5, 118-122, https://doi .org/10.1038/ngeo1364.

Lee, Z. P., K. Carder, R. Arnone, and M. X. He, 2007: Determination of primary spectral bands for remote sensing of aquatic environments. Sensors, 7, 34283441, https://doi.org/10.3390/s7123428.

Loisel, H., L. Duforet, D. Dessailly, M. Chami, and P. Dubuisson, 2008: Investigation of the variations in the water leaving polarized reflectance from the POLDER satellite data over two biogeochemical contrasted oceanic areas. Opt. Express, 16, 12 905-12918, https://doi.org/10.1364/OE.16.012905.

Lubac, B., H. Loisel, N. Guiselin, R. Astoreca, L. F. Artigas, and X. Meriaux, 2008: Hyperspectral and multispectral ocean color inversions to detect Phaeocystis globosa blooms in coastal waters. J. Geophys. Res., 113, C06026, https://doi.org/10.1029/2007JC004451.

Martins, J. V., 2017: Tiny satellites poised to make big contributions to essential science. The Conversation, https://theconversation.com/smallsat-revolution -tiny-satellites-poised-to-make-big-contributions -to-essential-science-71440.

- , R. Fernandez-Borda, B. McBride, L. A. Remer, and H. M. J. Barbosa, 2018: The HARP Hyperangular Imaging Polarimeter and the need for small satellite payloads with high science payoff for Earth science remote sensing. Proc. IEEE Int. Geoscience and Remote Sensing Symp., Valencia, Spain, Institute of Electrical and Electronics Engineers, 6304-6307, https://doi.org/10.1109/IGARSS.2018.8518823.

McClain, C. R., 2009: A decade of satellite ocean color observations. Annu. Rev. Mar. Sci., 1, 19-42, https:// doi.org/10.1146/annurev.marine.010908.163650.

- , and Coauthors, 2002: Science and observation recommendations for future NASA carbon cycle research. NASA Tech. Memo. NASA/TM-2002210009, $182 \mathrm{pp}$.

— - and Coauthors, 2012: The Ocean Radiometer for Carbon Assessment (ORCA): Development history within an advanced ocean mission concept, science objectives, design rationale, and sensor prototype description. NASA Tech. Memo., NASA/TM-2012215894, 62 pp.

McKinna, L. I. W., P. J. Werdell, and C. W. Proctor, 2016: Implementation of an analytical Raman scattering correction for satellite ocean-color processing. Opt. Express, 24, A1123-A1137, https://doi.org/10.1364 /OE.24.0A1123.

Meskhidze, N., L. A. Remer, S. Platnick, R. Negrón Juárez, A. M. Lichtenberger, and A. R. Aiyyer, 2009: Exploring the differences in cloud properties observed by the Terra and Aqua MODIS sensors. Atmos. Chem. Phys., 9, 3461-3475, https://doi.org/10.5194 /acp-9-3461-2009.

Miller, D. J., Z. Zhang, S. Platnick, A. S. Ackerman, F. Werner, C. Cornet, and K. Knobelspiesse, 2018: Comparisons of bispectral and polarimetric retrievals 
of marine boundary layer cloud microphysics: case studies using a LES-satellite retrieval simulator. Atmos. Meas. Tech., 11, 3689-3715, https://doi .org/10.5194/amt-5111-3689-2018.

Mishchenko, M. I., B. Cairns, J. E. Hansen, L. D. Travis, R. Burg, Y. J. Kaufman, J. V. Martins, and E. P. Shettle, 2004: Monitoring of aerosol forcing of climate from space: analysis of measurement requirements. J. Quant. Spectrosc. Radiat. Transfer, 88, 149-161, https://doi.org/10.1016/j.jqsrt.2004.03.030.

—, I. V. Geogdzhayev, W. B. Rossow, B. Cairns, B. E. Carlson, A. A. Lacis, L. Liu, and L. D. Travis, 2007a: Long-term satellite record reveals likely recent aerosol trend. Science, 315, 1543, https://doi.org/10.1126 /science.1136709.

— - and Coauthors, 2007b: Accurate monitoring of terrestrial aerosols and total solar irradiance: Introducing the Glory mission. Bull. Amer. Meteor. Soc., 88, 677-692, https://doi.org/10.1175/BAMS-88-5-677.

Mobley, C. D., J. Werdell, B. Franz, Z. Ahmad, and S. Bailey, 2016: Atmospheric correction for satellite ocean color radiometry. NASA Tech. Memo. NASA/ TM-2016-217551, 85 pp.

Mouw, C. B., and Coauthors, 2017: A consumer's guide to satellite remote sensing of multiple phytoplankton groups in the global ocean. Front. Mar. Sci., 4, 41, https://doi.org/10.3389/fmars.2017.00041.

Mueller, J. L., R. W. Austin, A. Morel, G. S. Fargion, and C. R. McClain, 2003: Ocean optics protocols for satellite ocean color sensor validation, revision 4: Introduction, background and conventions. NASA Tech. Memo. NASA/TM-2003-211621, 56 pp.

NASA, 2010: Responding to the challenge of climate and environmental change: NASA's plan for a climatecentric architecture for Earth observations and applications from space. NASA Rep., 49 pp., https:// smd-prod.s3.amazonaws.com/science-red/s3fs -public/atoms/files/Climate_Architecture_Final.pdf.

—, 2018a: PACE Ocean Color Instrument (OCI) concept design studies. PACE Tech. Rep. NASA/ TM-2018-219027, Vol. 7, 153 pp.

_ 2018b: Data product requirements and error budgets consensus document. PACE Tech. Rep. NASA/ TM-2018-219027, Vol. 6, 64 pp.

- 2018c: PACE mission formulation studies. PACE Tech. Rep. NASA/TM-2018-219027, Vol. 5, 108 pp.

Neukermans, G., and Coauthors, 2018: Harnessing remote sensing to address critical science questions on oceanatmosphere interactions. Elementa, 6, 71, https://doi .org/10.1016/http://doi.org/10.1525/elementa.331.

Nobileau, D., and D. Antoine, 2005: Detection of blueabsorbing aerosols using near infrared and visible (ocean color) remote sensing observations. Remote
Sens. Environ., 95, 368-387, https://doi.org/10.1016/j .rse.2004.12.020.

National Research Council, 2007: Earth Science and Applications from Space: National Imperatives for the Next Decade and Beyond. National Academies Press, $454 \mathrm{pp}$.

—, 2011: Assessing Requirements for Sustained Ocean Color Research and Operations. National Academies Press, $100 \mathrm{pp}$.

O’Reilly, J. E., S. Maritorena, B. G. Mitchell, D. A. Siegel, K. L. Carder, S. A. Garver, M. Kahru, and C. McClain, 1998: Ocean color chlorophyll algorithms for SeaWiFS. J. Geophys. Res., 103, 24 937-24 953, https://doi.org/10.1029/98JC02160.

Omar, A. H., M. Tzortziou, O. Coddington, and L. A. Remer, 2018: Plankton, Aerosol, Cloud, ocean Ecosystem mission: Atmosphere measurements for air quality applications. J. Appl. Remote Sens., 12, 042608, https://doi.org/10.1117/1.JRS.12.042608.

PACE Science Definition Team, 2018: Pre-Aerosols, Clouds, and ocean Ecosystem (PACE) Mission Science Definition Team report. PACE Tech. Rep. NASA/TM-2018-219027, Vol. 2, 316 pp.

PACE Science Team, 2018: Polarimetry in the PACE mission: Science Team consensus document. PACE Tech. Rep. NASA/TM-2018-219027, Vol. 3, 29 pp.

Platnick, S., M. D. King, S. A. Ackerman, W. P. Menzel, B. A. Baum, J. C. Riedi, and R. A. Frey, 2003: The MODIS cloud products: Algorithms and examples from Terra. IEEE Trans. Geosci. Remote Sens., 41, 459-473, https://doi.org/10.1109/TGRS.2002.808301.

— and Coauthors, 2018: Cloud retrievals in the PACE mission: PACE Science Team consensus document. PACE Tech. Rep. NASA/TM-2018-219027, Vol. 4, 50 pp.

Remer, L. A., and Coauthors, 2005: The MODIS aerosol algorithm, products, and validation. J. Atmos. Sci., 62, 947-973, https://doi.org/10.1175/JAS3385.1.

Roesler, C. S., and M. J. Perry, 1995: In situ phytoplankton absorption, fluorescence emission, and particulate backscattering spectra determined from reflectance. J. Geophys. Res., 100, 13 279-13 294, https://doi.org/10.1029/95JC00455.

Seftor, C. J., G. Jaross, M. Kowitt, M. Haken, J. Li, and L. E. Flynn, 2014: Postlaunch performance of the Suomi National Polar-Orbiting Partnership Ozone Mapping and Profiler Suite (OMPS) nadir sensors. J. Geophys. Res. Atmos., 119, 4413-4428, https://doi .org/10.1002/2013JD020472.

Siegel, D. A., S. Maritorena, N. B. Nelson, D. A. Hansell, and M. Lorenzi-Kayser, 2002: Global distribution and dynamics of colored dissolved and detrital organic materials. J. Geophys. Res., 107, 3228, https:// doi.org/10.1029/2001JC000965. 
— A. C. Thomas, and J. Marra, 2004a: Views of ocean processes from the Sea-Viewing Wide Field-of-View Sensor (SeaWiFS) mission: Introduction to the second special issue. Deep-Sea Res. II, 51, 911-912, https://doi.org/10.1016/S0967-0645(04)00091-8.

,$- \ldots$, and,$- 2004 \mathrm{~b}$ : Views of ocean processes from the Sea-Viewing Wide Field-of-View Sensor mission: Introduction to the first special issue. Deep-Sea Res. II, 51, 1-3, https://doi.org/10.1016/j .dsr2.2003.12.001.

_ , S. Maritorena, N. B. Nelson, and M. J. Behrenfeld, 2005: Independence and interdependencies among global ocean color properties: Reassessing the biooptical assumption. J. Geophys. Res., 110, C07011, https://doi.org/10.1029/2004JC002527.

— , and Coauthors, 2016: Prediction of the export and fate of global ocean net primary production: The EXPORTS science plan. Front. Mar. Sci., 3, 22, https://doi.org/10.3389/fmars.2016.00022.

Signorini, S., B. A. Franz, and C. R. McClain, 2015: Chlorophyll variability in the oligotrophic gyres: Mechanisms, seasonality, and trends. Front. Mar. Sci., 2, 1, https://doi.org/10.3389/fmars.2015.00001.

Smirnov, A., and Coauthors, 2009: Marine Aerosol Network as a component of Aerosol Robotic Network. J. Geophys. Res., 114, D06204, https://doi .org/10.1029/2008JD011257.

Snik, F., T. Karalidi, and C. U. Keller, 2009: Spectral modulation for full linear polarity. Appl. Opt., 48, 1337-1346, https://doi.org/10.1364/AO.48.001337.

Stamnes, S., and Coauthors, 2018: Simultaneous polarimeter retrievals of microphysical aerosol and ocean color parameters from the "MAPP" algorithm with comparison to high-spectral-resolution lidar aerosol and ocean products. Appl. Opt., 57, 2394-2413, https://doi.org/10.1364/AO.57.002394.

Tanré, D., Y. J. Kaufman, M. Herman, and S. Mattoo, 1997: Remote sensing of aerosol properties over oceans using the MODIS/EOS spectral radiances. J. Geophys. Res., 102, 16 971-16 988, https://doi .org/10.1029/96JD03437.

Torrecilla, E., D. Stramski, R. A. Reynolds, E. MillanNunez, and J. Piera, 2011: Cluster analysis of hyperspectral optical data for discriminating phytoplankton pigment assemblages in the open ocean. Remote Sens. Environ., 115, 2578-2593, https://doi .org/10.1016/j.rse.2011.05.014.

Torres, O., A. Tanskanen, B. Veihelmann, C. Ahn, R. Braak, P. K. Bhartia, P. Veefkind, and P. Levelt, 2007: Aerosols and surface UV products from Ozone Monitoring Instrument observations: An overview. J. Geophys. Res., 112, D24S47, https://doi .org/10.1029/2007JD008809. van Amerongen, A. H., 2018: SPEXone: A compact multi-angle spectro-polarimeter. Int. Conf. on Space Optics, Chania, Greece, European Space AgencyCentre National d'Études Spatiales, 111800L1-111800L-14, https://doi.org/10.1117/12.2535940.

Vanbauce, C., J. C. Buriez, F. Parol, B. Bonnel, G. Seze, and P. Couvert, 1998: Apparent pressure derived from ADEOS-POLDER observations in the oxygen A-band over ocean. Geophys. Res. Lett., 25, 31593162, https://doi.org/10.1029/98GL02324.

Vandermeulen, R. A., A. Mannino, A. R. Neeley, P. J. Werdell, and R. Arnone, 2017: Determining the optimal spectral sampling frequency and uncertainty thresholds for hyperspectral remote sensing of ocean color. Opt. Express, 25, A785-A797, https:// doi.org/10.1364/OE.25.00A785.

Waquet, F., B. Cairns, K. Knobelspiesse, J. Chowdhary, L. D. Travis, B. Schmid, and M. I. Mishchenko, 2009: Polarimetric remote sensing of aerosols over land. J. Geophys. Res., 114, D01206, https://doi .org/10.1029/2008JD010619.

Werdell, P. J., and Coauthors, 2018: An overview of approaches and challenges for retrieving marine inherent optical properties from ocean color remote sensing. Prog. Oceanogr., 160, 186-212, https://doi .org/10.1016/j.pocean.2018.01.001.

Xiong, X., J. Sun, X. Xie, W. L. Barnes, and V. V. Salomonson, 2010: On-orbit calibration and performance of Aqua MODIS reflective solar bands. IEEE Trans. Geosci. Remote Sens., 48, 535-546, https://doi .org/10.1109/TGRS.2009.2024307.

Yu, H., and Coauthors, 2006: A review of measurementbased assessments of the aerosol direct radiative effect and forcing. Atmos. Chem. Phys., 6, 613-666, https://doi.org/10.5194/acp-6-613-2006.

— L. A. Remer, R. A. Kahn, M. Chin, and Y. Zhang, 2013: Satellite perspective of aerosol intercontinental transport: From qualitative tracking to quantitative characterization. Atmos. Res., 124, 73-100, https:// doi.org/10.1016/j.atmosres.2012.12.013.

Yuan, T., L. Oreopoulos, M. Zelinka, H. Yu, J. R. Norris, M. Chin, S. Platnick, and K. Meyer, 2016: Positive low cloud and dust feedbacks amplify tropical North Atlantic multidecadal oscillation. Geophys. Res. Lett., 43, 1349-1356, https://doi .org/10.1002/2016GL067679.

Zibordi, G., and Coauthors, 2009: AERONET-OC: A network for the validation of ocean color primary products. J. Atmos. Oceanic Technol., 26, 1634-1651, https://doi.org/10.1175/2009JTECHO654.1.

— , C. Donlon, and A. Parr, 2014: Optical Radiometry for Ocean Climate Measurements. Academic Press, $722 \mathrm{pp}$. 